\title{
Fotoğraf ve Yıkım Estetiği: 11 Eylül 2001 İkiz Kuleler Saldırı Fotoğrafları Örneği
}

Photography and Aesthetics of Destruction: The Example of September 11, 2001 Twin Towers Attack Photos

\section{Aslı ERCIYES TOSUN1}

Araştırma Makalesi / Research Article

Geliş Tarihi / Received: 29.06.2021

Kabul Tarihi / Accepted: 26.07.2021

Doi: 10.48146/odusobiad.962793

\begin{abstract}
Atıf / Citation: Erciyeș Tosun, A., (2021). "Fotoğraf ve Yıkım Estetiği: 11 Eylül 2001 İkiz Kuleler Saldırı Fotoğrafları Örneği” ODÜSOBIAD 11(2), 629-646, doi: 10.48146/odusobiad.962793
\end{abstract}

\section{Öz}

Yıkım fotoğrafları barbarlık ve uygarlık arasındaki modern, aydınlanmacı ve rasyonel sınırları yıkar ve silikleștirir. Şiddet sarmalı ile kuşatılmış bir dünyanın görsel imgelerini üreten fotoğraflar aynı zamanda insanın gizlemeye çalıştığı yönlerini de gözler önüne serer. Fotoğraf bizi hem tanık hem de sanık sandalyesine oturtarak şiddet ile birlikte gelen yıkımın abartılı, büyüleyici, fantastik, şok edici, kendinden geçiren, gösterişçi, meydan okuyucu görüntüsünden haz aldığımızı itiraf ettirmeye çalışır. Bu haz ahlaki ve vicdani bir sorgulama yaşatma potansiyeline sahip olsa da yıkım estetiği olarak adlandırabileceğimiz estetik bir hazdır. Bu estetik haz temelde yücelik ve güzellik duyguları üzerinden alınmaktadır. Psikanalitik, felsefi vb. farklı açıklamalar getirilse de yıkımdan, imhadan kaynaklanan estetik hazzın kökeni kültür ve zihniyet kavramlarıyla da ilişkilidir. Çünkü kültür ve zihniyet duygular için referans işlevi görmektedir. Bu çalışmada sosyolojik ve antropolojik metinlerden yola çlkarak 11eylül 2001 tarihinde New York'ta ki İkiz kulelere yapılan saldırıya ait çeşitli fotoğrafçıların fotoğrafları üzerinden yıkım estetiğinin kültürel ve zihinsel kökenleri incelenmiștir.

Anahtar Kelimeler; Yıkım, Estetik, Fotoğraf, Kültür, Zihniyet.

\begin{abstract}
Destruction Photos breaks down and blurs the modern, enlightened and rational boundaries between barbarism and civilization. The photograph, which produces the visual image of a world surrounded by the spiral of violence, also reveals the aspects that people try to hide.The photograph tries to make us admit that we take pleasure in the exaggerated, fascinating, fantastic, shocking, ecstatic, pretentious, challenging image of the destruction that comes with violence by sitting us both in the witness and the accused's chairs. Although this pleasure has the potential to cause a moral and conscientious questioning, it is an aesthetic pleasure that we can call the aesthetic of destruction. This aesthetic pleasure is basically taken over the feelings of sublimity and beauty. Psychoanalytic, philosophical, etc. Although different explanations are offered, the origin of aesthetic pleasure arising from destruction and annihilation is also related to the concepts of culture and mentality. Because culture and mentality serve as a reference for emotions. This article examines the cultural and mental origins of the aesthetics of destruction through the photographs of various photographers of the attack on the Twin Towers in New York on September 11,2001, using sociological and anthropological texts.
\end{abstract}

Keywords: Destruction, Aesthetic, Photography, Culture, Mentality.

\section{Giriş}

21. yüzyıl 20. Yüzyılın yıkım mirasını devralırken; fotoğraf bu mirasın görsel kaydı, ışıkla yazılan veraset belgesi olmuştur. Kitleler bu yıkım mirasını fotoğraflar üzerinden yeniden canlandırmaktadır. Çünkü yaşadığımız evren gelişen bilgi, iletişim ve dijital teknolojileriyle birlikte fotoğraflarla kuşatılmış, fotoğraflarla anlamlandırılan, neredeyse fotoğraflarla nefes alan fotografik bir evren haline dönüşmüştür.

${ }^{1}$ Sorumlu Yazar, Dr. Öğr. Üyesi, Van Yüzüncü Yıl Üniversitesi Güzel Sanatlar Fakültesi, Van, aslierciyes@hotmail.com, ORCID: 00000002-4000-7202 
Bu evrenin en temel özelliklerinden birisi de tıpkı Walter Benjamin'in öngördüğü gibi gelişen teknolojilerle birlikte her şeyin daha da estetikleştirilmiş olmasıdır. Kuşkusuz buna yıkımın, imhanın İmmanuel Kant'ın yüce ve güzel kavramları çerçevesinde, korku, dehşet, büyülenme, trajedi gibi unsurlarla estetikleştirilmesi de dahildir. Susan Sontag yıkım estetiğini yıkımın estetiği, yıkıma yol açarken ve kargaşa yaratırken gözlenen güzellikler olarak değerlendirmektedir (Sontag, 2015: 281). Görüntüler üzerinden gerek binaların, nesnelerin gerekse bedenlerin yıkımının estetikleștirilmesi ile yıkım kitleler için daha da çekici hale getirilmektedir. Kitleler Norbert Elias'ın ve Emile Durkheim'in vurguladığı uygarlık sürecinin, maddi ilerlemenin dayattığı ahlak ve vicdan anlayışının engellemelerine rağmen yıkım görüntülerinden heyecanlanmakta, bu görüntülere ilgi göstermekte, büyülenmekte ve estetik bir haz duymaktadırlar. Kușkusuz kitlelerin yıkımdan duydukları haz ilkel toplumlara kadar uzanmaktadır. Marcel Mauss, Marvin Harris, Georges Bataille gibi antropologlar ile Johan Huizinga, Marc Bloch, Julius R. Ruff vb. tarihçilerin ilkel topluma, ortaçağa ve erken modern döneme dair metinleri insanların yıkıma ve yıkım ritüellerine, gösterilerine karşı ilgilerini ve duydukları hazzı kültür ve zihniyet üzerinden açıklamaya çalışmışlardır. Bu metinler armağan kültürüne ve zihniyetine göndermede bulunmaktadır. İtibar, prestij, onur, meydan okuma, statü, gösteriș ve rekabeti merkeze alan, nesnelerin ve bedenlerin abartıll, aşırı ve gösterişçi bir biçimde yıkımlarına-imhalarına dayalı armağan kültürü (potlaç) bir görsel şölen niteliğindedir. (Tosun, 2017:341-342)

Duygu, düşünce, anlam ve dolayısıyla estetik kodlar kültür ve zihniyet tarafından belirlenmektedir. Dolayısıyla kitlelerin yıkım fotoğraflarından aldıkları estetik haz bu kültürel ve zihinsel kodlar üzerinden gerçekleşmektedir. Bu makale ağırlıklı olarak Susan Sontag metinlerine atıfta bulunarak 11 Eylül 2001 tarihinde New Yok'ta İkiz Kulelere (Dünya Ticaret Merkezine) yapılan saldırı fotoğrafları üzerinden yıkım estetiğinin kültürel ve zihinsel kökenini incelemeyi amaçlamaktadır.

\section{Estetik ve Yıkımın Estetiği}

Etimolojik olarak estetik sözcüğü, "Yunanca Aisthanesthai (duymak, algılamak), aisthesis (duygu, duyum) sözcüklerinden gelmektedir. Günümüzdeki anlamıyla ilk kez kullanılışı 1750 tarihindedir. Alman filozofu Baumgarten 1750'de yayımladığı Aesthetica adlı yapıtında, akıla göre daha aşağı düzeydeki duyulardan gelen bilginin bilimin üzerinde dururken felsefe tarihinde estetik sözcüğünü ilk kullanan filozof olmaktadır" (Doğan, 1975: 7). Aesthetica'nın daha ilk sözlerinde Baumgarten, estetiği Aesthetica "( özgür sanatlar teorisi, aşağı bilgi teorisi, güzel üzerine düşünme ve akla benzer bir yeti bilimi) est scientia cognitionis sensitivae (estetik, duyusal bilginin bilimidir)" olarak tanımlamıștır (Tunalı, 1998: 14). Ancak bir bilim olarak estetiğin tanımı üzerinde belirli bir uzlaşma bulunmamaktadır. Estetiğin tanımıyla ilgili tartışmalar iki temel yaklaşım üzerinden ilerlemektedir. İlk yaklaşım estetiğin temel konusunun sanatın evrim yasaları ve sanatsal yaratının özü olduğudur. Bu yaklaşıma göre estetik genel bir sanat kuramıdır. İkinci yaklaşım ise estetik ile genel sanat kuramı birbirinden bağımsız iki ayrı bilim olduğunu savunmaktadır. Genel sanat kuramı sanattaki evrim yasalarını ve sanatsal yaratının özünü merkeze alırken estetik sanatta ve gerçeklikte güzelin bilimi olarak ele alınmaktadır (Ziss, 1984: 7-8). Sözlük tanımlamalarına bakıldığında farklı sözlüklerde yapılan estetik tanımlamalarının güzellik odaklı olduğu görülmektedir. Türk Dil Kurumu Türkçe sözlügün tanımına göre estetik sanatsal yaratının genel yasalarıyla sanatta ve hayatta güzelliğin kuramsal bilimi, güzel duyu olarak tanımlanmıştır (Parlatır ve ark. 1988: 732). Oxford sanat ve sanatçlar sözlüğünde ise estetik güzellik ve tat sorularıyla ilgilenen felsefe dalı olarak tanımlanmıştır (Chilvers, 1990: 4). Felsefe sözlüğünde estetik ayrıca sanat felsefesi olarak ta adlandırılır. Sanat deneyimi, değeri yaratımı ve bunlarla ilgili sorunların çözümü ve analizi ile ilgili felsefe dalıdır (Lacey, 1996: 5). Estetik Petit Robert sözlüğünde doğada ve sanatta güzelin bilimi; güzelin kendine özgü kavranışı, Webster'in Seventh New Collegiate sözlüğünde güzelliğe ilişkin, ya da onunla uğraşan, Das Grosse Deutsche sözlüğünde ise özellikle doğada ve sanatta güzel olanın temellerini ve yasalarını kapsayan bilgi olarak tanımlanmıștır (Doğan, 1975: 8). Ancak estetik, güzelliğin yanı sıra farklı değerleri de kapsamaktadır. "Estetiğin kapsamı içerisine yüce, trajik, komik, zarif, ilginç, çocuksu ve hatta çirkin değeri de girer. Bütün bu değerlerin, en az güzellik kadar estetik ile ilgisi olduğu gibi, onların estetik birer anlamı da vardır" (Tunalı, 1998: 15). Bu değerlere iyi, dramatik, hoş, alımlı değerleri de eklenebilir (Doğan, 1975: 8).

Estetiğin güzelliğin yanı sıra yüce, trajik gibi değerleri de içermesi ve bu değerlerin korku, dehșet ve büyülenmeyi de beraberinde getirmesi yıkım estetiğinin ve çalıșmaya konu olan 11 Eylül saldırı fotoğraflarının anlaşılmasını kolaylaştırmaktadır.

Sözlük tanımı itibariyle yıkım estetiği kırılmıș, yıkılmış, imha edilmiş, çökmüş şeylerde güzellik ve çekicilik bulmaktır(https://www.urbandictionary.com/define.php?term=Destruction\%20Aesthetics).Ylkım estetiğine yönelik bir başka tanımlama da Susan Sontag tarafından yapılmıştır. Sontag yıkımın estetiğini, metinlerinde ifade ettiği gibi binalar, şehirler, insanlar ile ilgili yıkıma yol açarken ve kargaşa yaratırken gözlenen güzellikler olarak tanımlamaktadır (Sontag, 2015: 281). Geniş anlamda yıkım estetiğine yönelik 
tanımların merkezinde yer alan güzellik ve çekicilik değerlerine yukarıda ifade edildiği gibi yüce, trajik, dramatik, çirkin, iyi, hoş gibi değerleri de eklemek gerekmektedir. Alman filozof Immanuel Kant'ın estetik üzerine yaptığı değerlendirmelerde yıkım estetiği ile bağlantılı olarak güzellik ve yücelik duyguları ön plana çıkmaktadır. Kant'a göre felaket tasviri korku içeren bir zevk uyandırır. Gece yücedir, gündüz güzeldir. Yüce harekete geçirir, güzel büyüler. Dehşet duygusu uyandıracak bir şekilde derin yalnızlık yücedir. Yüce her zaman büyük olmalıdır güzel küçük te olabilir. Trajedi yücelik duygusu uyandırır (Kant, 2010: 8-15).

Sanat tarihi boyunca pek çok yıkım imgesi ile karşılaşılmaktadır. "Yunan mitolojisinde acıyla kıvranan Laokoon ve ikiz oğullarını temsil eden heykel grubu, İsa'nın ıstırabının resim ve heykel alanındaki sayısız versiyonları ve Hıristiyan din şehitlerinin gaddarca idamlarıyla vb. yıkım-imha temalı sonsuz sayıda görsel malzeme bulunmaktadır" (Sontag, 2004: 39-40). Goltzius, Benvenuto Cellini, Goltzius, Titian, Jacques Callot, Francisco de Goya, John Martin, Joseph Mallord William Turner, Hieronymus Bosch, Sebastiano Ricci, Thomas Cole, Picasso gibi bir çok sanatçı kimi eserlerinde yıkım-imha temasını ele alarak yıkımı ve imhayı estetikleștirmeye çalışmıştır.

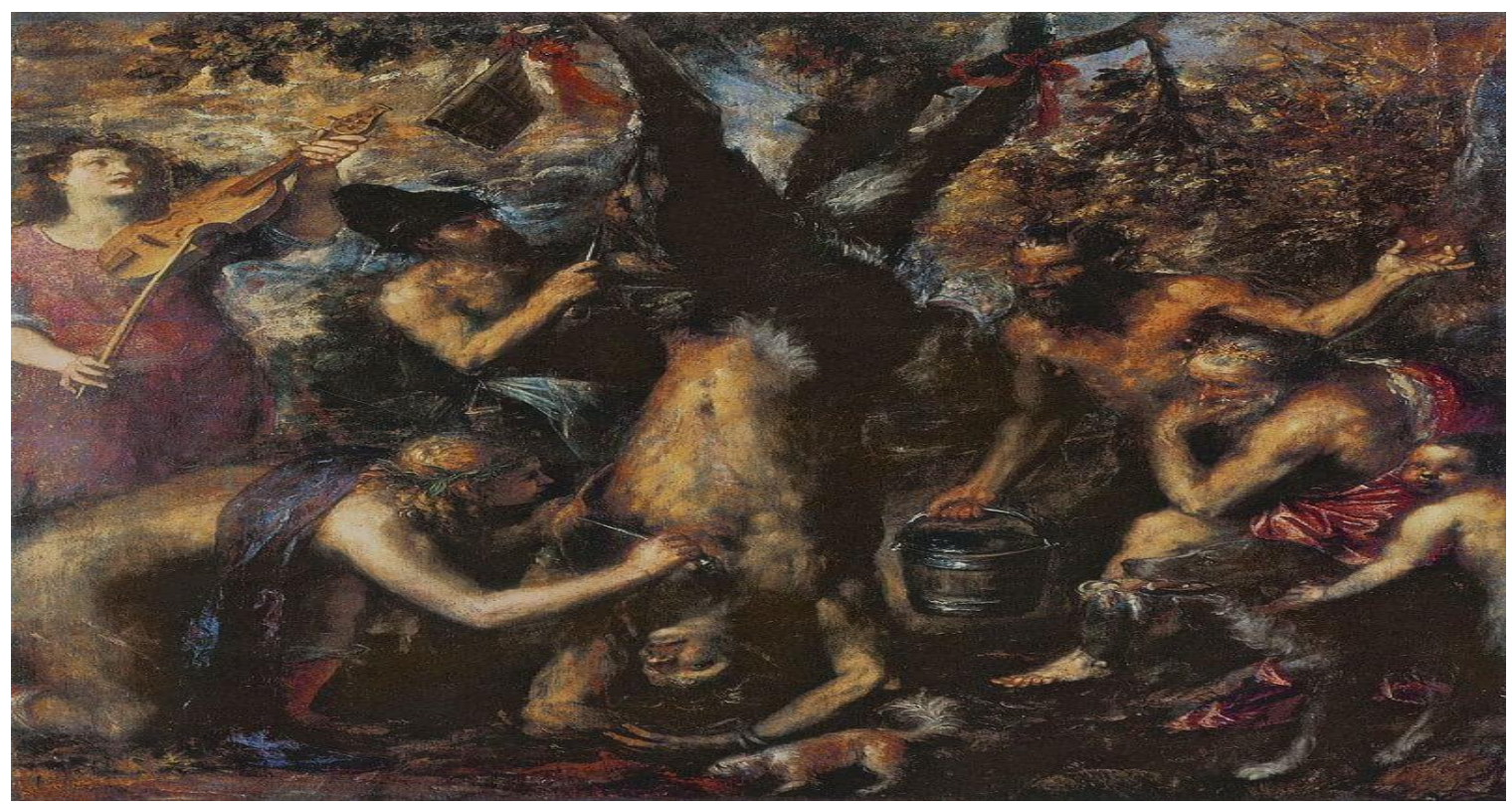

Görsel 1. Titian, Marsyas'ın Derisinin Yüzülüşü (1576).

Fotoğrafın keşfiyle birlikte yıkım estetiğine yönelik en çarpıcı örneklerin savaş fotoğrafları olduğu söylenebilir. Kuşkusuz insanlık tarihinde gerçekleşen en büyük yıkımlar I. ve II. Dünya Savaşları sırasında yaşanmıştır. Dolayısıyla yıkımın, yani bedenlere, nesnelere ve insan tarafından inşa edilen yapılara yönelik imhanın kaynağı olarak görülen savaşın fotoğraflanması yıkım estetiği için bir zemin oluşturmaktadır. Ünlü savaş esteti Ernst Jünger'in 1930'da ifade ettiği gibi fotoğrafsız savaş olmaz (Sontag, 2004: 67). Savaş fotoğrafları tanıklığın yanı sıra savaş (yıkım-imha) eylemini sırayla abartan, yayan, dramatize eden ve saptıran estetik üretimlerdir (Warren, 2006: 1636).

Söz konusu yüce, dehşet, trajik, büyülenme, güzellik, çirkinlik gibi estetik değerler olduğunda fotoğraf yıkımın-ölümün bu estetik değerler üzerinden temsilinde her türlü sözlü anlatımdan daha büyük bir ağırlığa sahip olmaktadır. 1914 ile 1918 yılları arasında yayınlanan ve neredeyse hepsi imzasız olan ve şiddetin yol açtığı dehşet ve yıkımdan izler yansıtan, cesetlerin her tarafa saçıldığı, dümdüz edilmiş Fransız köyleri vb. savaş fotoğrafları genelde epik bir anlayıșın izlerini taşımaktadır. Kuşkusuz I. Dünya Savaşında olduğu gibi II. Dünya Savaşında da dehşet verici, korkunç anlar fotoğraflanmıştır (Sontag, 2004: 20-24). Savaş bir insanlık trajedisidir ve savaş fotoğrafları yücelik perspektifinden değerlendirilebilir. Kant'çı bakış açısıyla trajedi yücelik duygusu uyandırır. Savaş fotoğrafçılığı potansiyel olarak bedensel parçalanma ile yakın ilişki kurar (Bate, 2009: 95). 


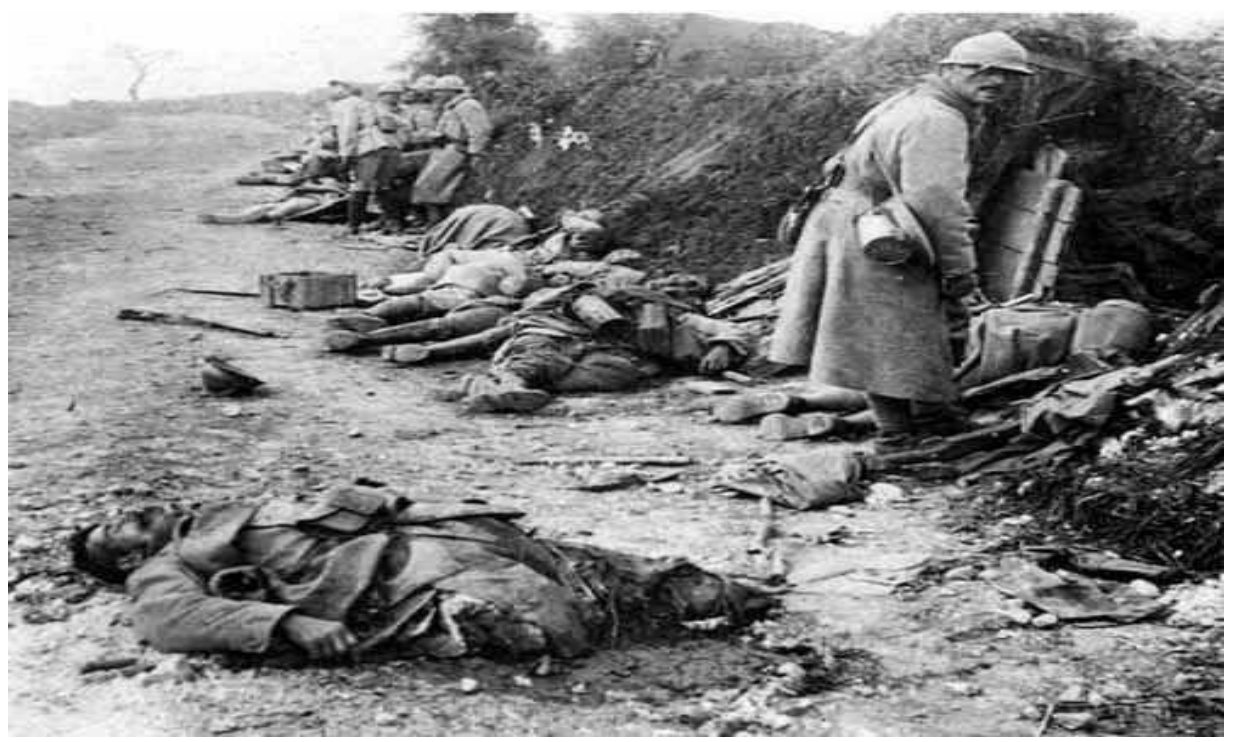

Görsel 2. İsimsiz, I. Dünya Savaşı.

Immanuel Kant'ın güzellik ve yücelik duyguları çerçevesinde savaşın, yıkımın, ölümün yüceltilmesine, dolayısıyla yıkımın estetikleștirilmesine yönelik yaklaşımlar göz önüne alındığında akla Fütürizm ve Fütürizmle bağlantılı Faşizm gelmektedir. Kuramsal çerçevede yıkım estetiğinin izlerini İtalyan şair Filippo Tommaso Marinetti'nin Etiyopya' da ki sömürge savaşı üzerine yazdığı Fütürist manifestosunda görmek mümkündür. Manifestoda şu ifadelerle yer almaktadır:

"Biz fütüristler, yirmi yedi yıldan beri savaşa anti-estetik bir damga vurulmasına karşı isyan halindeyiz. Bunun yerine șunu söylüyoruz: Savaș güzeldir, çünkü gaz maskeleri, dehșet salan megafonları, alev makineleri ve küçük tankları aracllığıyla, insanın boyunduruk altına alınmış bir mekanizma üzerindeki egemenliğini kurar. Savaș güzeldir, çünkü bir düşü (insan bedeninin madenileştirilmesi düşünü) uygulamaya sokar. Savaş güzeldir, çünkü yemyeşil çayırların rengini makineli tüfeklerin alev saçan orkideleriyle zenginleștirir. Savaș güzeldir, çünkü tüfek seslerini, top gürlemelerini, ateşkes haykırışlarını, kokuları ve çürümüş etlerden yayılan iğrençlikleri bir senfoniye dönüștürür. Savaș güzeldir, çünkü büyük tankların, geometrik dizilișle uçan filoların, yanan köylerden yükselen duman halkalarının ve savaşa özgü bașka benzeri şeylerinki gibi yeni bir mimari yaratır. Fütürizmin şairleri ve sanatçıları! Savaş estetiğinin bu ilkelerini hiç aklınızdan çlkarmayı" "

denmektedir (Benjamin, 2013: 93). Kuramsal çerçevede Marinetti'den sonra yıkım estetiğinin izlerini Faşizm ve Faşist estetikte bulmak mümkündür. Faşist estetiğin yıkım estetiği ile doğrudan ilişkisi bulunmaktadır. Savaş Alman modernizmini bir yıkım estetiğine yönlendiren başlıca yıkım olarak anlaşılır (Evers, 2013: xii). Walter Benjamin'in faşizm üzerine yaptığı değerlendirmeler faşist estetik ve yıkım estetiği arasındaki bağı göstermektedir. Benjamin'e göre faşistler tıpkı Marinetti'nin fütürist manifestosunda olduğu gibi savaşı yani yıkımı-imhayı yüceltirler. Fașizm, Dünya batıp gitse de sanat olsun demektedir. Faşizm, Marinetti'nin açılkça belirttiği üzere "savaştan, teknolojinin değiștirmiş olduğu algı duyusunun sanatsal yolla karşılanmasının sağlanmasını bekler. Bunu en açık biçimiyle sanat için sanat düşüncesinin hayata geçirilmesinde görebiliriz. Homeros'un devrinde Olimpos'taki tanrıların gözünde seyirlik bir şey olan insanlık, artık kendisi için bir seyir malzemesidir. İnsanlığın kendine yabancılaşması o raddeye varmıştır ki, kendi yıkımını dahi birinci kalite bir estetik haz olarak yaşayabilecektir. Faşizmin siyaseti estetize etmesinin bizi getirip getireceği yer burasıdır" (Benjamin, 2013: 92-95). Baudrillard ise Faşizmin insanları büyüleyebilmiş tek modern biçim olduğunu ve Faşist politikanın bir ölüm estetiğine sahip olduğunu ifade etmektedir (Baudrillard, 2013: 77-78). Faşist sanat boyun eğmeyi yüceltir; akılsızlığı över; ölümü çekici hale getirir (Sontag, 2008: 217). Faşist ruh hali ile çelişki, abartma ve çarpıtma, biçimini bozma estetiği arasındaki bağlantı önemlidir (Braun, 1996: 273). İmha görüntülerindeki belirli estetik hazlar bu faşist ruh hali ile de ilişkilidir. Faşizm uzmanı siyaset bilimci Robert O. Paxton Faşizmi diğer özelliklerinin yanı sıra aşağılanma kaygısı tarafından işaretlenmiş politik davranış biçimi olarak tanımlar (Paxton, 2005: 218). Dolayısıyla faşist estetik I. Dünya Savaşında yaşanan yenilgiden kaynaklanan aşağllanma, küçük düşürülme, utanç korkusu ve bu korkuyu aşmak üzerinden beslenmiştir. 
Baudrillard'a göre Benjamin'in faşist sistemde varlığını kanıtladığı politik, estetik ve sapıkça hazzı bizler bugün genelleştirilmiş bir üretim sistemi aracılığıyla almaya çalışıyoruz. Onu depolitize, ideolojiden yoksun bir hazza dönüştürmeye çalışıyoruz (Baudrillard, 2016: 338-339). Kuşkusuz yıkım estetiği bağlamında 11 Eylül saldırı fotoğrafları göz önüne alındığında bu fotoğraflardan alınan estetik hazzın kapitalist üretim sistemi ile ilişkili olarak faşizmden ve faşist estetikten bağımsız olduğu söylenebilir. Ancak yıkım estetiği ile ilişkili olarak faşizmden öncede faşizmden sonrada var olan estetik hazzı tetikleyen rekabet, meydan okuma, aşağılanma, utanç, onur, prestij ve itibar duyguları ile doğrudan bağlantılı aşırılık, abartı, çelişki ve gösteriş kavramları dikkate alınmalıdır. En basit anlatımla ortaçağda bedenin parçalara bölünmesi ile gerçekleşen idam gösterilerinden ve aşırılık, abartı ve biçimini bozma içeren bu idam gösterilerinin sanatsal temsillerinden alınan estetik hazzın doğal olarak Faşizm ile ilgisi bulunmamaktadır. Burada vurgulanması gereken faşizm olgusundan yüzyıllar önce gerçekleștirilen bu idam gösterilerinin de fașist estetikte olduğu gibi biçimini bozma, aşırılık, gösteriş ile abartı içermesidir. Dolayısıyla Baudrillard'ın deyişiyle ideolojiden yoksun bir estetik haz geçmişte olduğu gibi kültürün ve zihniyetin alanına girmektedir. Aynı durum 11 Eylül saldırı fotoğrafları için de geçerlidir.

\section{Yıkım Estetiğinin Kültürel Zihinsel Arka Planı}

Kültür ve zihniyet kapsamları itibarıyla sanat ile dolayısıyla estetik ile doğrudan bağlantılıdır. Edward Tylor'un geniş kabul gören tanımıyla kültür, "insanın toplumun bir üyesi olarak edindiği bilgi, inanç, sanat, ahlâk, yasa, görenek ve başka herhangi bir yetenek ya da alışkanlığı içeren o karmaşık bütün olarak tanımlamaktadır" (Burke, 2008: 41). Zihniyet ise Alex Mucchielli'nin tanımıyla bir toplumsal grubun örtük referans sistemidir. Bu toplumsal grup paylaşılan ortak anlayış sayesinde türdeștir. Söz konusu referans sistemi şeylerin belli bir biçimde görülmesini, dolayısıyla bu anlayışla uyumlu tepkiler ve davranışlar gösterilmesini olanaklı kılmaktadır. Zihniyet bir grup için, çevredeki kültürün içerdiği norm ve değerlerin özümsenmesi ile edinilen ortak bir referans çerçevesidir. Zihniyet bir dünya görüşünün taşıyıcısıdır (Mucchielli, 1991: 7-21). Kültür ile olduğu gibi estetik değerler ve zihniyet tipleri arasında da bir ilişki bulunmaktadır. Çeşitli uygarlık ve toplumlara ait zihniyet tiplerini belirleyen etmenlerin en önemlilerinden birinin estetik değerler olduğu belirtilmektedir. Bouthoul'a göre özgün bir sanat yoksa özgün bir zihniyet de yoktur (Adanır, 1994: 24). Kültür ve zihniyet birbirinden ayrılmaz bağlarla birbirlerine kenetlenmiştir. Birinden söz etmenin zorunlu olarak diğerinden söz etmek anlamına gelmektedir. Birini anlamadan diğerini anlayabilmek mümkün değildir. Zihniyet bir yandan oluşmuş bir kültürü yeniden üretir ve gereksinim duyulduğunda yeniden yaratırken; kültür de zihniyetin yeniden üretimine ve değişim ve dönüşüm gereksinimine yol açan koşullar oluştuğundaysa değişmesine ve dönüşmesine katkıda bulunur (Adanır, 2003: 23-26).

Dünyada yıkımı-imhayı ve yıkımın-imhanın nasıl gerçekleştirilmesi gerektiğini merkezine alan en eski kültür armağan kültürü (potlaç) ve zihniyetidir. Franz Boas, Ruth Benedict, Marcel Mauss ve Claude LeviStrauss gibi antropologlar ilkel toplum üzerine yaptıkları çalışmalarda kapitalizm öncesi evrensel bir kültür olan Armağan kültürünün izlerine rastlamışlardır. İskandinavya'dan Anadolu'ya, Asya'dan Avrupa'ya, Kuzey Amerika'dan Güney Amerika'ya kadar bir çok farklı coğrafyada görülen ve Marcel Mauss'un beş kıtada yapılmış antropolojik çalışmalardan yola çıkarak evrensel bir kültür olarak tanımladığı potlaç, yani armağan kültürü Mauss'un armağan adlı çalışmasıyla kuramsal zemine oturtulmuştur (Adanır, 2002: 159). Potlaç yani Armağan kültürü ritüeller üzerine temellenen törensel bir büyü düzenidir (Adanır, 2000: 109). "Potlaç dini, mitolojik ve şamanistik nitelikler taşımaktadır. Çünkü potlaçların yükümlülüğünü alan şefler atalarını ve tanrılarını temsil etmekte ve canlandırmaktadırlar" (Mauss, 2011: 275).

Armağan kültürü ve zihniyeti karşılıklı yükümlülük üzerine inşa edilmiştir. Bu kültürde ve zihniyette herkes veren el, alan el ilişskisi çerçevesinde aldığı armağanları altta kalmamak adına fazlasıyla iade etmek zorundadır. Bunu gerçekleştiremeyenler yüzlerini yani onurlarını, prestijlerini ve itibarlarını kaybederler. $\mathrm{Bu}$ kültürde ve zihniyette saygınlığını yitirmek ruhunu yitirmek anlamına gelmektedir ve her şey itibar, onur ve prestij kazanmak içindir. Armağan kültüründe ve zihniyetinde armağan verme ritüelleri yıkım, rekabet, çatışma, yok etme, meydan okuma temaları içermektedir (Mauss, 2011: 215-279). Potlacın temel amacı rakibin verdiğinden daha çoğunu vermek, rakibin yok ettiğinden daha fazlasını yok etmektir (Harris, 1995: 98). Böylece en üstün ve en prestijli olan belirlenmektedir. Potlaç ta en çok yıkım yapan galip gelmekte ve en büyük ünü kazanmaktadır (Canetti, 2006: 223). Armağan kültüründe ve zihniyetinde armağanlar bilinen nesnelerin yanı sıra hakaret sözcükleri, yumruklar, mızraklar yani yıkımı gerçekleştiren araçlar da olabilmektedir. Mauss'un Armağan adlı çalışmasında yararlandığı İskandinav metinlerini inceleyen William Ian Miller'e göre "Pagan İzlanda'sında birisine firlatılan mızraklar, kırılan kemikler ve hakaretler karşılık verilmesi gereken armağanlardır” (Miller, 1996: 182). Alain Caillé, olumlu armağanların yanı sıra olumsuz armağanların da bulunduğunu, kötü hareketlerin, hakaretlerin, yaralamaların, öç, intikam ve misillemelerin hatta büyülemenin bir armağan olduklarını iddia etmektedir. Caillé’ye göre bu armağan 
tipinin en meşhur örneği potlaçtır (Bruni ve Zamagni, 2013: 47). Potlaç üzerine değerlendirmelerde bulunan ekonomi tarihi profesörü Avner Offer bu çerçevede patolojik armağanlardan söz eder. Offer hakaret, nefret ve intikam sarmalıyla karşılaştığımızı ve bu patolojik armağan döngüsünün kendisini düello, kan davası ve tutku suçları ile gösterdiğini öne sürer (Offer, 1997: 455). Armağan kültüründe yıkım uygulamalarında iki önemli faktör bulunmaktadır. Bunlardan birincisi savaş temasıdır. Kwakiutl potlacının sembolü bir sopanın ucuna takılan bıçaktır. Potlaç mülklerin imhasını amaçlayan bir savaştır. Mülklerle savaşılır ve rakibi ezmek, küçük düşürmek ve aşağılamak için mülkler yok edilir. İkincisi kurban temasıdır. Bir mülk yok ediliyorsa bu o mülkün canı olduğu anlamına gelmektedir. Kurban vermenin amacı zorunlu olarak geri verilmesi gereken bir bağıșta bulunmak demektir. Kölelerin öldürülmesinin, değerli yağların yakılmasının, bakır eşyaların denize atılmasının ve zenginlerin evlerinin ateşe verilmesinin tek amacı sadece gücü, zenginliği ve bunlara karşı ilgisizliği göstermek değildir, aynı zamanda yaşayan örnekleriyle birbirine karıșan ruhlara ve tanrılara isimlerini taşıyan varlıkları kurban etmektir (Mauss, 2011: 229-271). Georges Bataille'in de belirttiği gibi "armağan potlacın tek biçimi değildir; rakiplere meydan okuma, zenginliğin parlak biçimde imha edilmesiyle de mümkündür. Yok etmeler, kuramsal olarak armağanı alanların mitsel atalarına sunulduğu için, bu son yok etme biçimiyle potlaç dinsel kurban etmeye bağlanmaktadır. Bir Tlingit şefi rakibinin karşısına kölelerinin birkaçının boğazlayarak çıkar. Bu yok etmeye belirli bir süre sonra daha çok sayıda kölenin boğazlanmasıyla karşıllık verilir. Kuzey-Doğu Sibirya'nın en uç noktasında yaşayan Tchoukchi'ler, başka bir grubu şaşırtmak ve aşağılamak için büyük miktardaki köpek sürülerini öldürmüşlerdir. Amerika'nın Kuzey-Batı bölgesinde, yok edişler köylerin yakılması PotlaçArmağan kültürünün rutin uygulamalarıdır" (Bataille, 1999: 35). Benzer uygulamalara Marc Bloch'un ifadesiyle ortaçağ Avrupa'sında da rastlanmaktadır. Bir şövalye övünmek için atlarından 30 tanesini diri diri yaktırır. Bu prestij düellosu, bize ilkel toplamlardan haberler getiren bazı etnografların anlattıklarım hatırlatmaktadır (Bloch, 1983: 388). Tüm bunlar armağan kültürü ve zihniyeti ile onun merkezinde bulunan rekabet, meydan okuma, gösteriş, abartı, aşağılanma, küçük düşürme, karşılıklı yükümlülük, itibar, onur ve prestij kazanma ile ilişkilidir.

Yıkım estetiği bağlamında Armağan kültürünün-potlacın ve zihniyetinin en önemli özellikleri yok etmeimha-yıkım eylemlerinin gösterişli ve abartılı niteliğidir (Mauss, 2011: 357). Bedenlerin ve mülklerin imhası ve yıkımı tıpkı 11 Eylül saldırılarında olduğu gibi abartılı, gösterişçi ve çarpıcı bir biçimde gerçekleștirilmektedir. Huizinga'nın da ifade ettiği gibi potlaç büyük ve gösterişli bir seremonidir. Potlaç ta varlıkların imhası çarpıcı bir biçimde gerçekleștirilir (Huizinga, 2006: 84-85).

Farklı coğrafyalarda farklı dönemlerde gerçekleştirilen idam ritüelleri abartılı, aşırı ve gösterişçi imhaya dayalı ortak kültürel-zihinsel kodlar üzerinden ortak özellikler taşımaktadır. Marvin Harris'in ilkel topluma yönelik Yamyamlar ve Krallar adlı çalıșmasında Jesuit misyonerlerinin tanıklığına göre:

\begin{abstract}
"kurbanı şafaktan önce öldürmemek" önemlidir. Bu nedenle onlar önce onun sadece ayaklarını yakmalıydılar. $O$ odanın bir ucundan ötekine sendeleyerek yürürken bazı kişiler onun ellerini yakaladılar, var güçleriyle el kemiklerini kırdılar, bazıları da çubuklar kullanarak kulaklarını deldiler. Şimdi dört adam tutsağa işkence yapma görevini üstlendiler. Onun gözlerini yaktılar, kızgın baltaları omuzlarına vurdular ve yanan odunları boğazına ve rektumuna soktular. Artık ölmek üzere olduğu anlașılınca, cellatlardan biri onun bir ayağını, bir bașkası bir kolunu kesti ve hemen hemen aynı anda bir üçüncüsü başını omuzlarından ayırdı ve onu kalabalığa firlattı" (Harris, 1994: 155).
\end{abstract}

Filozof ve tarih profesörü Johan Huizinga Ortaçağın Gün Batımı adlı araştırmasında, "suçluların bedenlerinin parçalanıșının halk tarafından zevkle izlenmesini panayır eğlencesine benzetmiștir. Halk daha fazla zevk alsın diye işkenceler yetkililerce uzatılmaktadır. Parçalanan bedenler halka açık bir şekilde farklı alanlarda sergilenmektedir. Zavallıları yalvartan infazlar, halk onların uğradıkları işkencelerden daha fazla zevk alsın diye geciktirilmektedir" (Huizinga, 1997: 37). Erken Modern dönem Avrupa'sında da idamlar ortaçağ uygulamaları ile benzerlik taşımaktadır. 1757 yılında XV. Louis'e suikast girişiminde bulunan Damiens sonunda, uzuvları parça parça olduğunda, hekim daha fazla dayanamayacağını söylemiştir.

\begin{abstract}
"Darağacında, sonu gelmeden önce, Damiens en büyük işkencelere katlandı. Cellatların anlattıklarına göre bu dehşet verici işkenceler peş peșe uygulandı, göğsü ve uzuvları kerpetenlerle didik didik edildi, yaralarına kızgın yağ, kurşun vb. döküldü ve sonunda cellatların koșturduğu dört at uzuvlarını gövdesinden ayırdı. Yine de öyle dayanıkliydı ki onu parça parça etmeleri saatlerce sürdü: Sonunda, çaresiz, hala yaşayan gövde bıçakla dörde ayrıldı. Dörde bölmek, gövde parçalara ayrılmadan önce karnın yarılıp bağırsakların dışarı çıkarılması uygulamasında olduğu gibi, bağırsakların deşilmesinin bir üst aşaması șeklinde ortaya çıkmış ve uzun zaman devam etmiștir"
\end{abstract}

(Scott, 2001: 220-221). Armağan kültürünün hakim olduğu Çin'de (Simon, 2015: 9) gerçekleştirilen Lingchi yüz bıçakla ölüm adlı idam ritüellerinde de benzer yıkım yöntemleri kullanılmaktadır. 


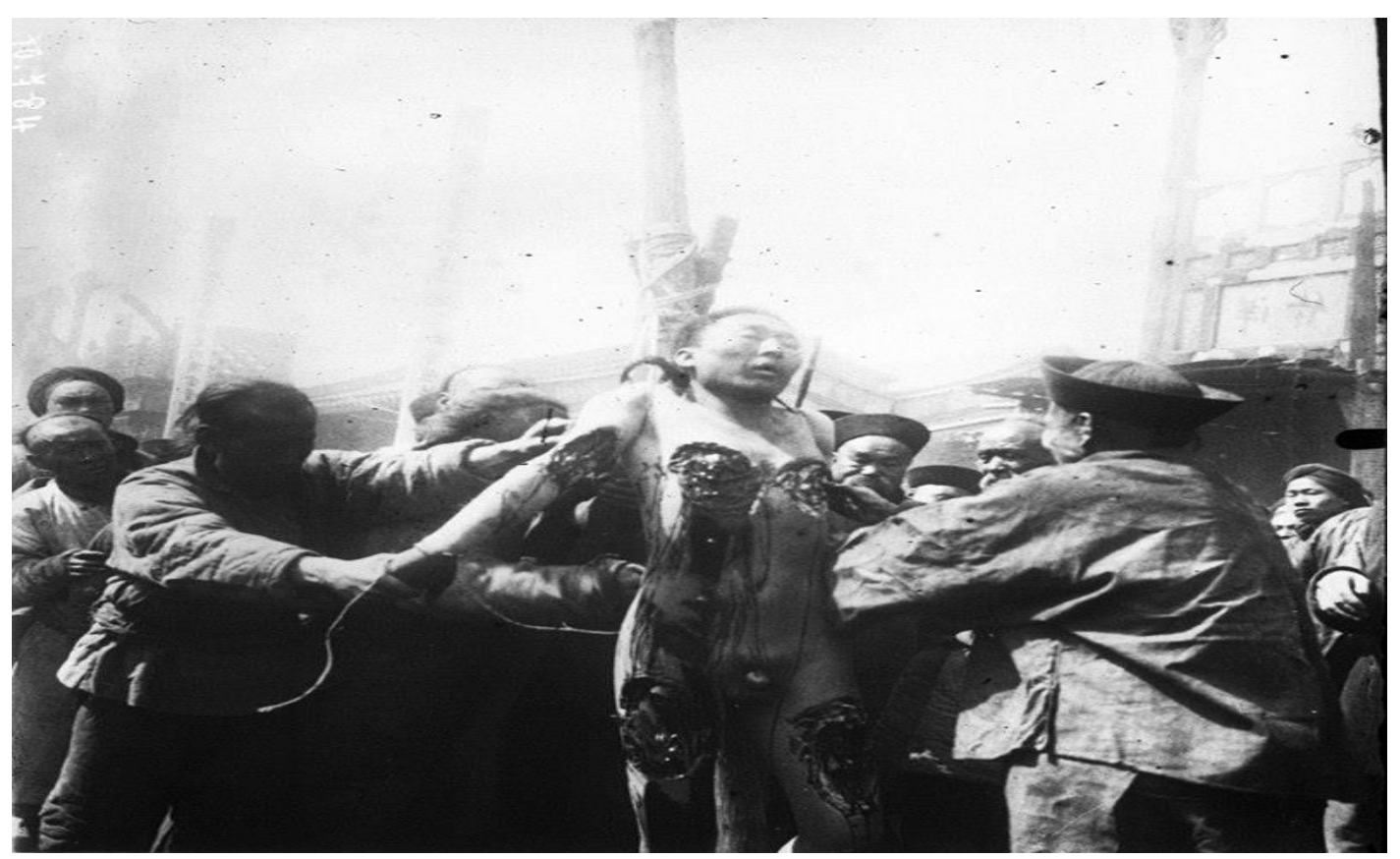

Görsel 3. Fransız asker tarafından çekilen fotoğraf, isimsiz (Pekin, 1905).

Armağan kültürünün hakim olduğu ilkel toplumlarda, ortaçağın feodal toplumlarında ve özellikle 20. yüzyılın başlarında Çin'de gerçekleştirilen idam ritüelleri göz önüne alındı̆̆ında tamamında yıkım estetiğinin abartılı, çarpıcı, aşırı ve gösterişçi tezahürlerini görmek mümkün olmaktadır.

Yukarıda verilen idam ritüellerinde amaç ilkel toplum için tanrılara yakışır bir armağan-kurban vermek iken Avrupa ve Çin'de idam edileni aşağılamak, yani kralın veya imparatorun itibarına ve otoritesine armağan vermektir. İdam ritüellerinde cesetleri parçalamak aynı zamanda onları küçük düşürmek, onuruyla oynamak, aşağılamak demektir (Ruff, 2011: 103).

Bedenin tanrılar, kral veya imparatorluk için abartılı, aşırı, çarpıcı ve gösterişçi bir biçimde imha edilmesi imhayı gerçekleştiren kabileye, krala veya imparatora armağan kültürünün kodları olan prestij, itibar, statü, saygınlık kazandırmaktadır.

11 Eylül 2001'de ikiz kulelere düzenlenen saldırının fotoğraflarını değerlendirmeden önce hatırlatılması gereken en önemli nokta Armağan kültürü ve zihniyetinin günümüzdeki yansımalarıdır. Jean Baudrillard "Simgesel Değiş Tokuş ve Ölüm" başlıklı çalışmasında Louis Dumont, J. T. Godbout ve Alain Caille'de olduğu gibi Batılı ya da Avrupalı toplumların potlaç kültüründen çıkıp geldiklerini resmen onaylayan açıklama ve yorumlar getirmektedir. Bunun yanı sıra Baudrillard günümüzde potlacın, yani birikime izin vermeyen Armağan kültürü ve zihniyetinin kapitalizm nedeniyle ortadan kaybolduğunu ancak ilkelerinin hala sürüp gittiğini ifade etmektedir (Adanır, 2015: 405-631). Özellikle görsel kültür potlacın ilkelerini canlı tutmaktadır. Amerikalı yazar Leonard Sweet Aztek kurban törenlerini referans göstererek filmlerin bedenin yıkımını, imhasını yücelttiğini ileri sürer. Ona göre imhayı, yıkımı merkezine alan felaket filmleri de postmodern potlaçtır (Sweet, 1999: 331-332). Benzer şekilde Amerikalı film eleștirmeni James Lewis Hoberman'da gökdelenlerin yıkımı vb. felaket filmlerine bakıldı̆̆ında potlacın geri döndüğünü iddia etmektedir (Elsaesser, 2004: 198). 11 Eylül saldırısı ve fotoğrafları da aynı düşünceyi desteklemektedir.

\section{Eylül Fotoğrafları ve Yıkım Estetiği}

11 Eylül saldırı fotoğrafları kendi mantığı içerisinde binaların gösterişçi ve abartılı bir şekilde yıkıma uğratıldığı-imha edildiği bir potlaç şöleninin fotoğraflanması olarak düşünülebilir. Saldırının temel motivasyonu potlacın temel motivasyonu olan intikam yani karşlık vermektir. Kapitalizm ilkel ritüellere özgü o yok etme eylemindekini andıran derin bir ahlâksızlık ve de ayartıcılıkla bize meydan okumaktadır. Bu tür bir meydan okumaya daha büyük bir meydan okumayla karşılık vermek gerekir (Baudrillard, 2011b: 207). Hatırlatmak gerekir ki bir karşılık verme biçimi olan intikam da bir armağandır. Karşılıklı yükümlülük gereği Amerika Birleşik Devletlerinin İslam dünyasına yönelik daha önce gerçekleştirdiği birinci körfez savaşı vb. saldırılara bir karşılık-karşı armağan verilmiştir. Saldırının amacı altta kalmamak adına alınanı 
fazlasıyla geri vererek Allah katında ve İslam aleminde itibar, prestij, onur kazanma çabasıdır. Armağan kültürü ve zihniyetinin motivasyonuyla gerçekleştirilen saldırı (karşı armağan) insanlık tarihinde bu güne kadar görülmemiş bir şekilde ilgi çekmiş, heyecan yaratmış ve sanatın alanına çekilerek estetikleştirilmiştir.

Estetik 11 Eylül saldırısını fotoğraflamanın bir parçasıdır (Prosser, 2017: 12). Baştan çıkarmanın ve büyülemenin bir parçasıdır. 11 Eylül 2001 tarihinde Dünya Ticaret Merkezine diğer bir deyişle ikiz kulelere yapılan terör saldırıları insanlık tarihinde derin izler bırakmış, öfke, korku, şaşkınlık, yüce, güzellik hayranlık, büyülenme vb. karışık duygular uyandırmıștır. Unutulmamalıdır ki duygular kültür ile doğrudan bağlantılıdır. Kültür çekirdek duygu sistemini kültürel olarak mevcut olaylara göre ayarlayarak biyolojik duyguları düzenler. Böylece bireyler ne hakkında duygusallaşacaklarını öğrenirler (Matsumoto ve Hwang, 2012: 96).

Immanuel Kant’a göre güzel sanatların asıl üstünlüğünü gösterdiği yer, doğada çirkin ya da nahoş olabilen şeylerin güzel tasvirlerini verebilmesidir. Öfke tanrıçaları, hastalıklar, savaşın yıkımları ve bunlar gibi şeyler, çok güzel bir şekilde tasvir edilebilir, hatta resmedilebilir (Schaper, 2005: 178). 11 Eylül fotoğrafları bunu başarabilmiştir. Amerikalı profesör Miles Orvell son yirmi yılın görsel kültüründe en popüler türlerden birisinin de Dünya Ticaret Merkezi'nden Katrina Kasırgasına ve daha yakın zamanda Sandy Kasırgası gibi imha-yıkım ve enkaz fotoğrafları olduğunu ifade etmektedir.

\begin{abstract}
"11 Eylül saldırılarını özellikle fotoğraf aracılı̆ıyla deneyimledikçe aynı zamanda imha-yıkım gösterileri tarafindan büyüleniyoruz. Bu büyülenmeyi yıkıcı yüce (After 9/11) olarak adlandırıyorum. Maddi tahrip gösterisi ile yoğun keder ve kayıp duygusunun neden olduğ u fotoğraf felaketin özel bir ikonografisini yaratmıştır. Felaket-Imha- yıkım fotoğrafları bize belirsiz ve sarsıcı bir estetik haz vermiștir" (Orvell, 2013: 647).
\end{abstract}

Baudrillard'da 11 Eylül saldırılarında imkansızın gerçekleşmesi üzerine coşku ve dehşet karışımı bir atmosfer oluştuğunu, Kant'ın vurguladığı hayranlık uyandıran coşku ve ürkütücülüğün kendisini gösterdiğini ileri sürer (Baudrillard, 2015: 126).Yıkım sürecinde estetik teoriye uygun yıkım öncesi, yıkım anı ve yıkım sonrası olmak üzere üç aşama belirleyebiliriz. Yıkıcı bir eylemin zevki öncelikle maddenin hızlı dönüşümü sırasında meydana gelen görsel, işitsel ve dokunsal uyaranlardan türer. Bu yıkım eğlencesinin en yoğun olduğu zamandır. Bu zamanda meydana gelen süreç estetik teoriyi içeren değişkenlerin kullanımı ile tanımlanabilir. Büyüklük, karmaşıklık ve beklenmediklik gibi değișkenlerin varlığı veya yokluğu imhayıkım sürecinin az veya çok zevkli, haz verici olup olmadığını belirlemektedir (Allen ve Greenberger, 1978: 313). Baudrillard 11 Eylül saldırılarında imkansızın gerçekleşmesi üzerine coşku ve dehşet karışımı bir atmosfer oluştuğunu, Kant'ın vurguladığı hayranlık uyandıran coşku ve ürkütücülüğün kendisini gösterdiğini ileri sürer (Baudrillard, 2015: 126).

Bu bakıș açısıyla 11 Eylül saldırıları ve fotoğrafları coşkulu, ürkütücü, korkunç, hayranlık uyandıran, dehșet içeren, zevk ve haz verici bir estetik temsil olarak görülebilir. Aristoteles, "Poetika"nın dördüncü bölümünde gerçeklikte hoşlanmayarak baktığımız bir nesnenin özellikle tamamlanmış bir resim haline geldiğinde, bu kez ona hoşlanarak baktığımızı ifade ederek hayvanların ve cesetlerin resimlerini örnek verir (Aristoteles, 1987: 16). 11Eylül saldırılarının fotoğraflanması benzer etkiye, hoşlanmaya neden olmuş olabilir. Üstelik bu fotoğrafların çoğu trajik fotoğraflardır. "Tragedyanın görevi uyandırdığı acıma ve korku duygularıyla ruhu tutkulardan temizlemektir" (Aristoteles, 1987: 22). 11 Eylül saldırı fotoğrafları trajik bir temsil olarak fotoğrafa bakan öznelere ilahi bir katharsis süreci yașatabilme potansiyeline sahiptir. 


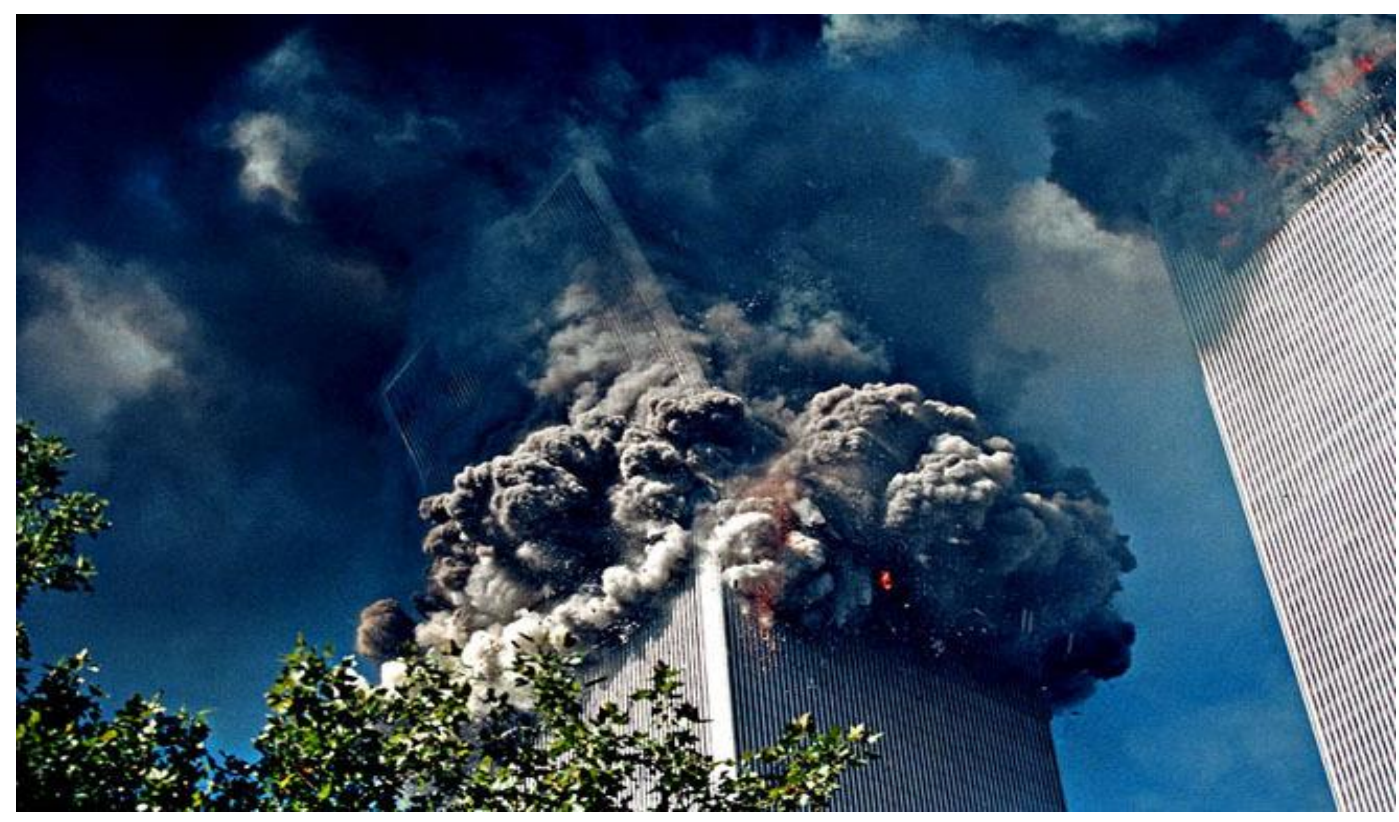

Görsel 4. Thomas Nilsson, İkiz kuleler (2001).

Kimi görüşler 11 Eylül saldırılarının bir sanat eseri olduğunu iddia etmektedir. Alman opera bestecisi Karlheinz Stockhausen'un 11 Eylül saldırıları hakkındaki düşünceleri bu çerçevede değerlendirilebilir.

\begin{abstract}
"11 Eylül saldırıları tüm evren için hayal edilebilecek en büyük sanat eseridir. Bir performansa odaklanıllyor ve sonra 5000 insanın öbür dünyaya bir anda gönderiliyor. Ben bunu yapamadım. Bu performansla karşılaştırıldığında biz besteciler bir hiçiz. Sanatçılarda bazen mümkün ve makul olanın ötesine geçmeye çalışırlar. Bu yüzden uyanalım ve biz kendimizi başka bir dünyaya açalım."
\end{abstract}

Profesör Richard Schechner'e göre performans çalışmaları açısından bakıldığında dünya ticaret merkezine yapılan saldırı bir performanstır. Planlanmış, prova edilmiş, sahnelenmiş ve hayal gücüne bulaşmış bir performans. 11 Eylül saldırısı doğrudan fütürist, anarşist ve diğer avangard manifestolar ve eylemler gibi görünür. Teröristler Tristan Tzaras'ın ikinci Dada manifestosunda ifade ettiği büyük felaket-yıkım gösterisini hazırlıyoruz düşüncesini hayata geçirmişlerdir. 11 Eylül saldırısı Burke ve Kant'ın yüce olarak adlandırdığı șeyin bir örneğidir. Çoğunda olmasa bile 11 Eylül saldırısı izleyicilerde Aristocu trajik acıma ve korku duyguları uyandırmıştır. Bu olaya bu şekilde baktığımızda şok, avangard sanat, trajedi veya intikam. 11 Eylül saldırısı Artaud'un vahşet tiyatrosu çerçevesinde 1938 yılında yayımladı̆̆ı "Artık Başyapıt Yok" başlıklı makalesindeki tekinsizlik savını sergilemiștir (Schechner, 2009: 1820-1828). Schechner'in ifadeleri 11 Eylül saldırısını ve fotoğraflarını doğrudan sanatın, estetiğin ve fotoğraf tarihinin alanına sokmaktadır. Uçakların binalara girmesi ve sonrasını yakalamak bize elektrik mühendisi olan fakat sonra bilimsel deneyler için fotoğraf çekmeye başlayan Harold Edgerton'un stroboscope kullanarak çektiği elmayı delip geçen mermi fotoğrafını hatırlatmaktadır (Orvell, 2006: 244). 


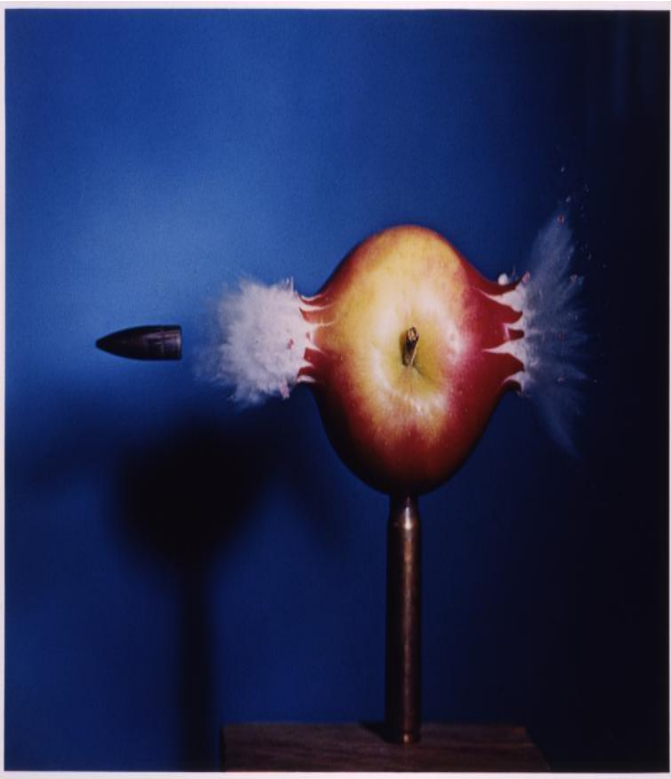

Görsel 5. Harold Edgarton, Apple, (1964).

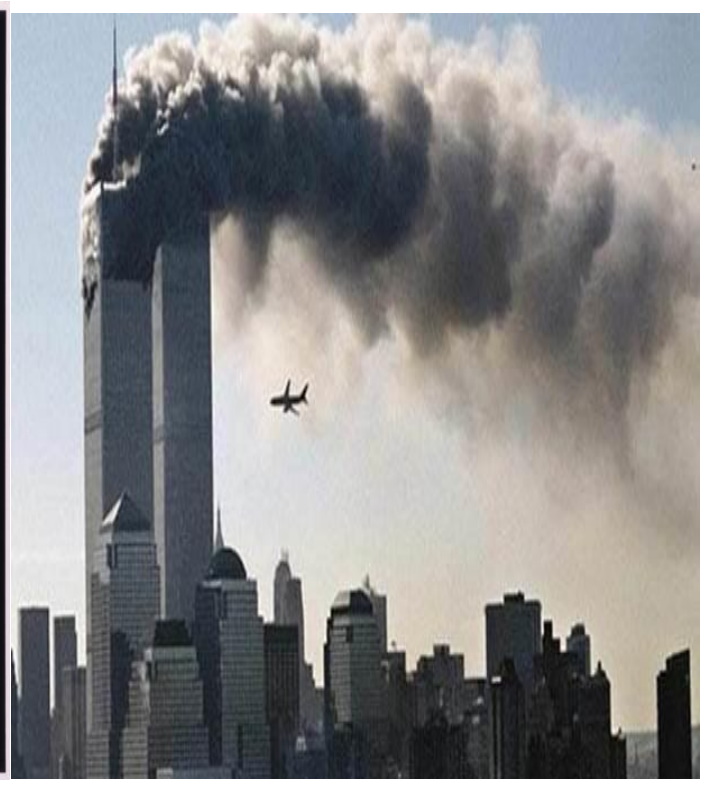

Görsel 6. İkiz Kuleler (2001).

Benzer bir durum 11 Eylül saldırısının ikonik fotoğraflarından birisi olan Richard Drew’un Düşen Adam adlı fotoğrafı ile Andy Warhol'un ünlü İntihar adlı çalışması için de geçerlidir. Andy Warhol'un Amerika'da ölüm serisinde felaket fotoğraflarını kullanması fotoğraf tarihindeki en büyük anlardan birisi olmuştur (Baker, 2005: 121).

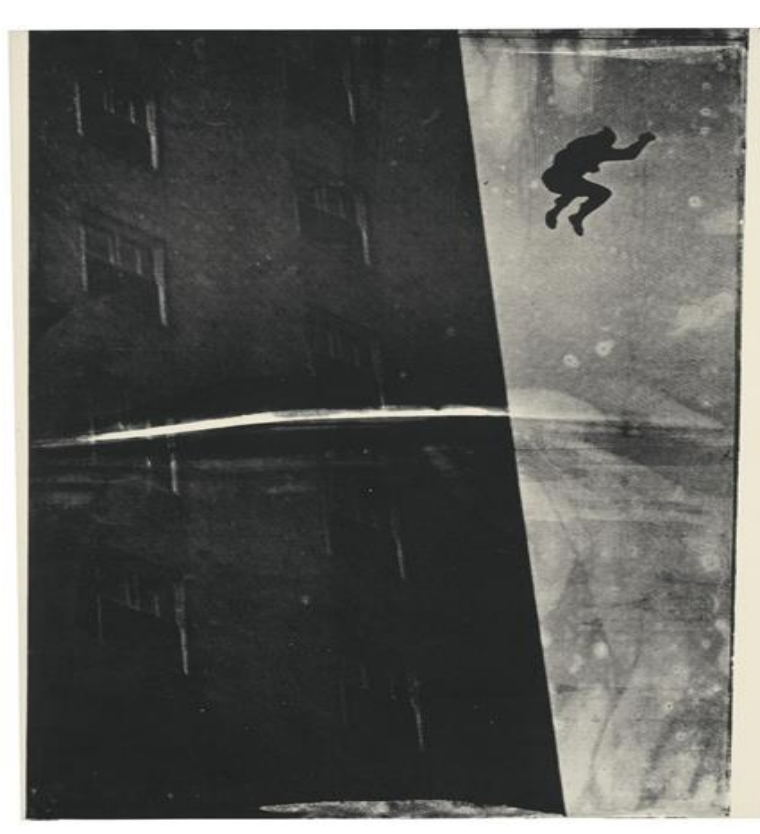

Görsel 7. Andy Warhol, İntihar (1964).

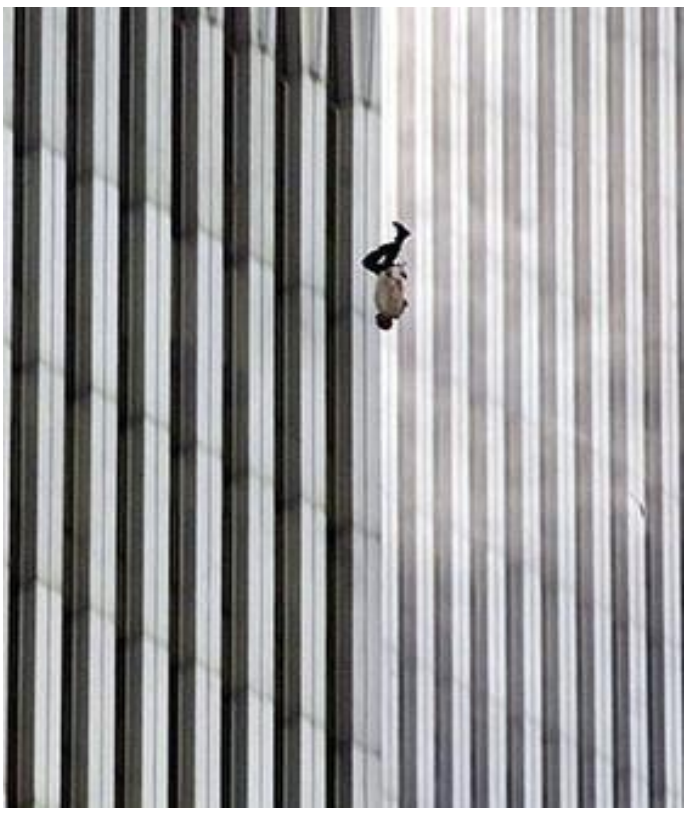

Görsel 8. Richard Drew, Düșen Adam (2001).

Friedrich Schiller' in XIX. yüzyılın başında yazdıkları 11 Eylül saldırılarının etkisini anlatır gibidir. Trajik yücenin en özgün biçimidir. Üzüntünün, korkunçluğun, iğrençliğin, aşırılığın ve dehşetin karşı konulmaz bir büyü ile üzerimizde cazibe, çekim yaratması insan doğasının genel bir olgusudur (Lousa, 2016: 374). İngiliz sanatçı Damien Hirst'de 11 Eylül saldırılarını sanat eseri olarak değerlendirmiştir. Ona göre 11 Eylül saldırısından sorumlu teröristlerin tebrik edilmesi, kutlanması gerekir. Çünkü sanatsal düzeyde hiç 
kimsenin mümkün olduğunu düşünemeyeceği şeyi başarmışlardır. 11 Eylül saldırısı kötüdür fakat bir sanat eseridir (Macneill, 2014: 184). Bir sanat eseri olarak 11 Eylül'ün doğasındaki kötülük onun varsayllan estetik gücünü veya güzelliğini tamamlar. Damien Hirst, 11 Eylül korkunç eylemlerinin temsilini takdir ederken Kantçı estetik/yansıtıcı yargı anlayışını benimsiyor gibidir. Sanatçının iddia ettiği gibi, görsel olarak çarpıcı sanat eseri, sorumluların tebrik edilmesi gereken bir şeydir, çünkü onlar muhtemelen sanatsal bașarı açısından daha önce kimsenin gitmediği yerlere gittiler. Teröristler olağan ve mümkün olanın sınırlarını aşan bir eylemde bulunmuşlardır. Bu nedenle onlar, Kant'ın tanımladığı gibi, yani insan ölçüsünü ve kavramsal düşüncenin gücünü aşan özerk bir varlık olarak güzelliğin gerçek özüne ulaşmayı bașarmıșlardır (Aretoulakis, 2016: 29-31). Jean Baudrillard'da 11 Eylül saldırısına dair düşüncelerini yüceltme duygusu, coşkunluk ve olağandışılık üzerinden ifade etmiştir (https://v3.arkitera.com/h13491serhan-adanin-jean-baudrillard-ile-soylesisi.html).

11 Eylül saldırı fotoğrafları sanat tarihine de göndermede bulunmaktadır. Jeffrey C. Alexander 11 Eylül saldırı görüntülerini Hieronymus Bosch'un kaotik resimleri ile ilişkilendirmiştir. Aleander'e göre adil ceza, cehennem ve lanet görüntüleri batının hayal gücünde derin ve tekrarlanan temalarıdır ve New York'un çarpışma alanı Hieronymus Bosch'un geç ortaçağ resimlerini hatırlatan kıyametin estetik arketipleri tarafından çerçevelenmiştir (Alexander, 2006: 103).

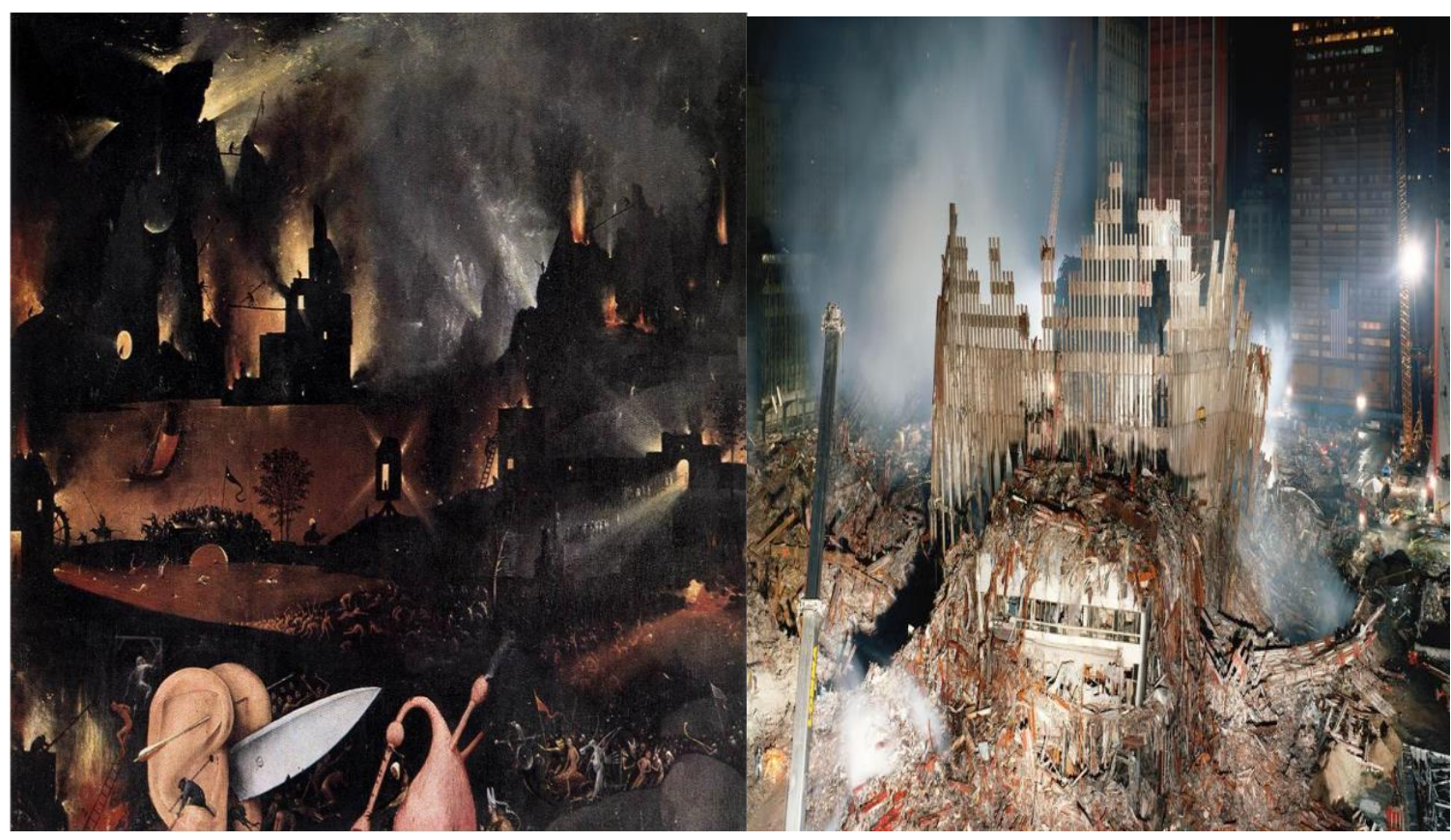

Görsel 9. Hieronymus Bosch, Dünyevi Zevkler Bahçesi (1504).

Görsel 10. Joel Meyerowitz, (2001).

Benzer durum J.M. William Turner'in çalışmasında da görülmektedir. 11 Eylül saldırı fotoğraflarında Joseph Mallord William Turner'ın The Burning of the Houses of Lords and Commons (1834) adlı tablosundan yansımalar varmış gibidir. Turner tıpkı 11 Eylül saldırısını görüntüleyen fotoğrafçılar gibi Lordlar ve Avam Kamarası'nın Yakılmasına tanıklık etmiş ve yangını resmetmiştir. 


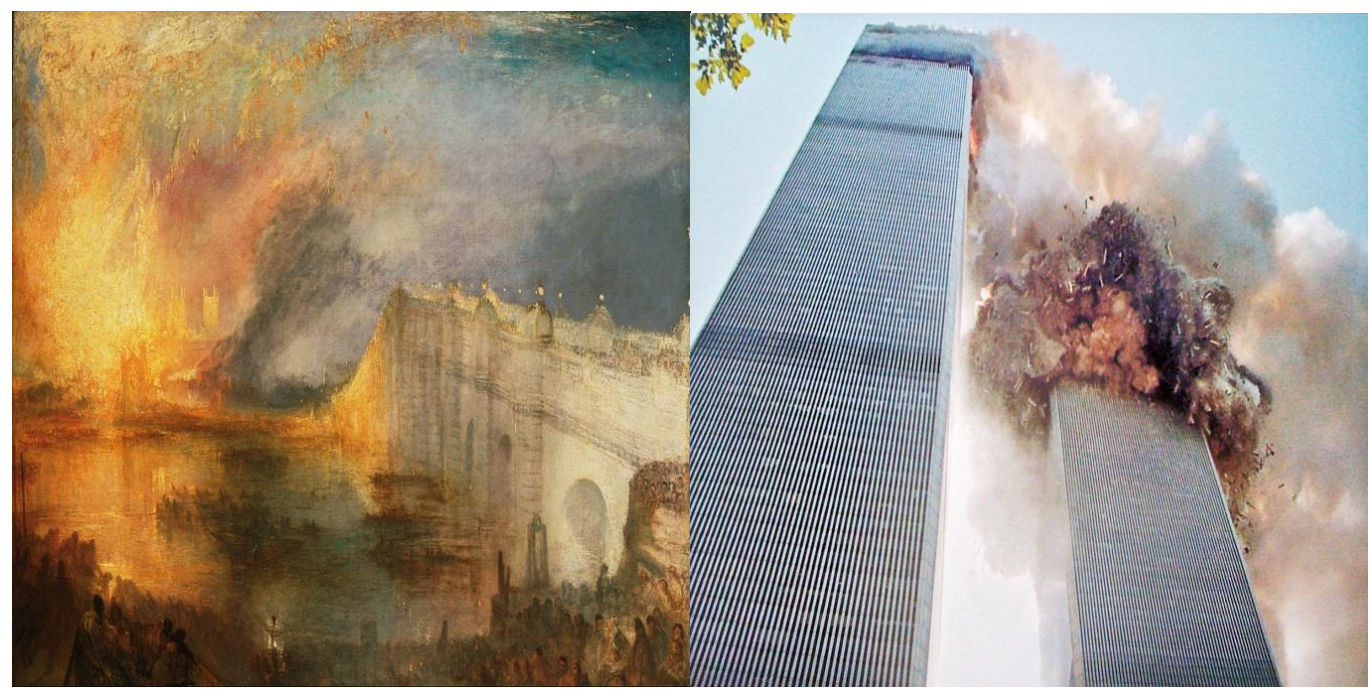

Görsel 11. J. M. William Turner, (1834).

Görsel 12. Bolivar Arellano, (2001).

11 Eylül saldırısının ve sonrasının tanıklığını yapan fotoğrafçıların görüşleri de güzellik kavramı üzerinden şekillenmektedir. Amerikalı foto muhabiri James Nachtwey yaşadığı anı anlatırken saldırıyı güzel kavramı üzerinden değerlendirmektedir;

"10:29'da gökyüzünde bir şelaleye benzeyen sesi duydum ve altında durduğum kuzey kulesi çökmeye başladı. Yaşamak için beș saniyem olduğunu anladım. Burada hayatta kalma şansım çok zayıftı. Beni öldürecekti ve orada fotoğraf çekecek kadar zamanım yoktu. Gökyüzüne doğru baktığımda kağıt, metal ve duman ile gerçekten çok güzel bir manzaraydı, görsel olarak çok çarpıcıydı, çekiciydi, müthişti. Hayatımda bu güne kadar gördüğüm en güzel șeylerdi" demektedir (Orvell, 2013: 663-664).

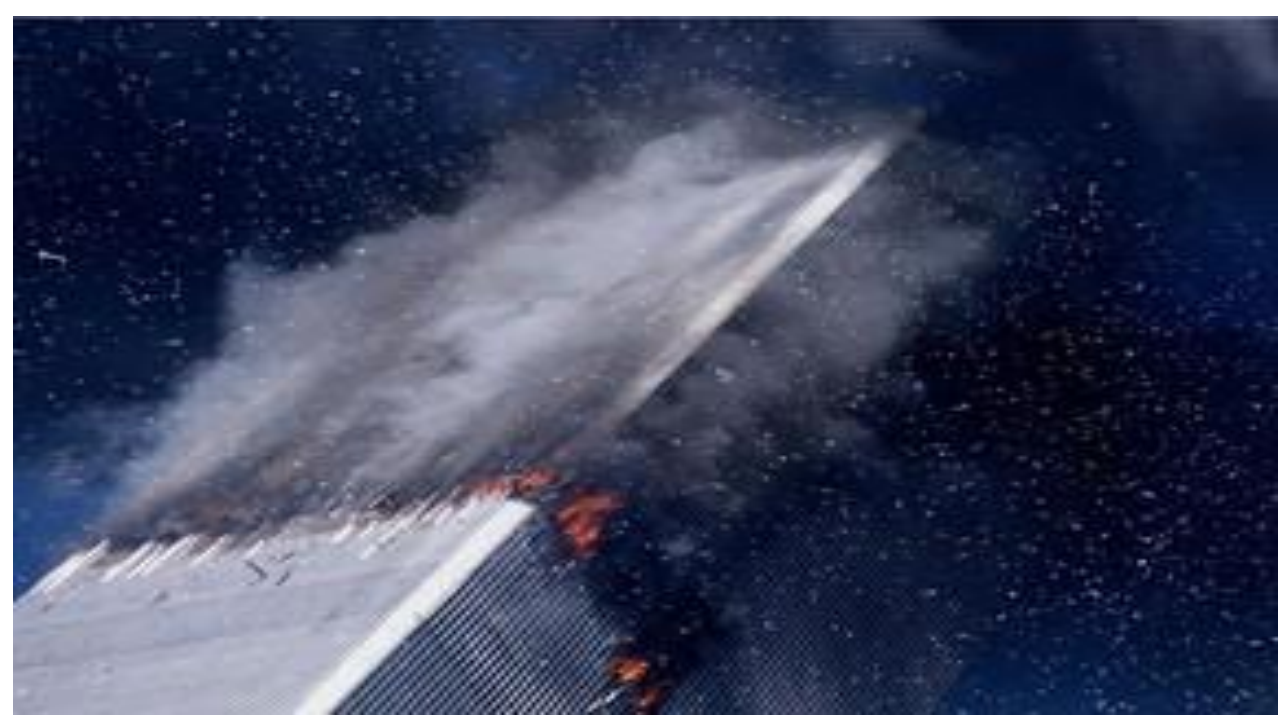

Görsel 13. Lyle Owerko, (2001).

Nachtwey'in yerini değiştirerek çektiği 11 Eylül fotoğrafları felaketin geldiği aşamayı ve saldırının ideolojik ve kültürel boyutunu vurgulamaktadır. 11 Eylül saldırıları Müslümanların Hac ziyaretinde yaptıkları șeytan taşlama pratiğinin farklı bir versiyonu olarak görülebilir. Radikal İslamcıların gözünde Amerika Birleşik Devletleri şeytanın somutlaşmış halidir. Bu kez şeytan uçaklarla taşlanmıştır. Armağan kültürü 
çerçevesinde hakaretler, mızraklar gibi taşlama da bir armağandır. Şeytanın yaptı̆̆ı kötülüklere karşı verilen bir armağan.

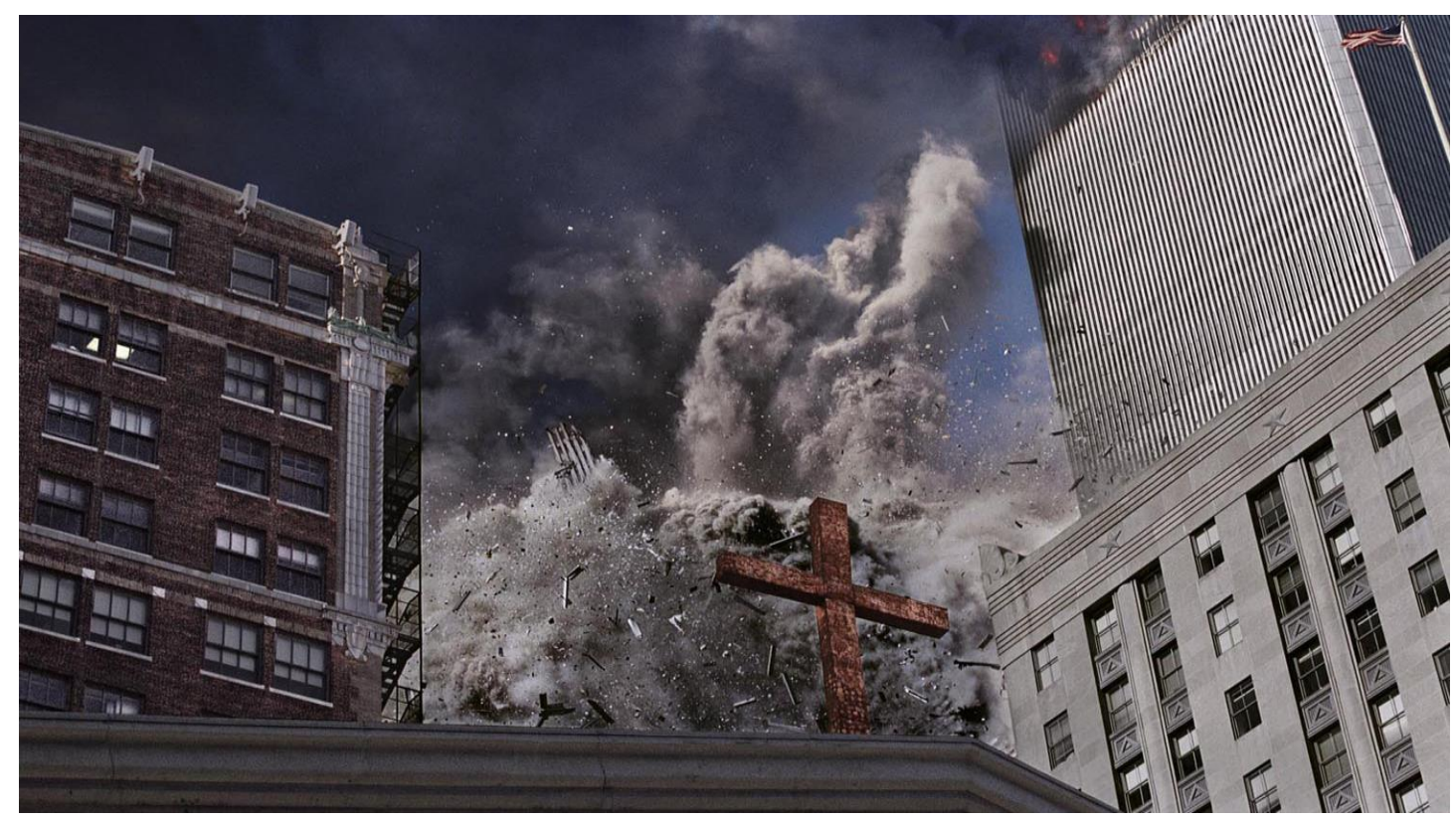

Görsel 14. James Nachtwey, Yaklaşan Kiyamet (2001).

Bir başka Amerikalı fotoğrafçı Joel Meyerowitz saldırı sonrası enkazı fotoğraflamıştır. Meyerowitz yıkıntının, enkazın korkunç fakat güzel bir his olduğunu ve bu korkunç güzellik ile anlaşmanın zor olduğunu ifade etmiştir (Orvell, 2013: 666).

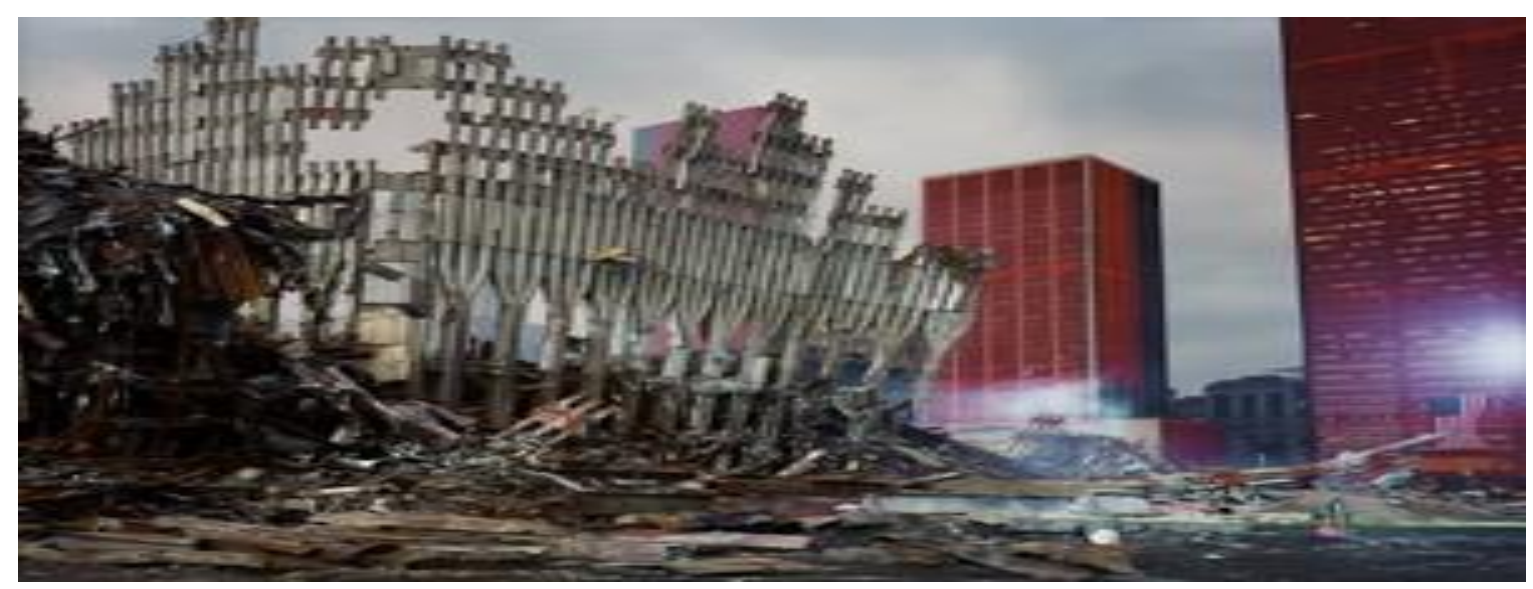

Görsel 15. Joel Meyerowitz, Korkunç Güzellik (2001).

Sontag'ın da belirttiği gibi yıkım manzarası da nihayetinde bir manzaradır. Burada söz konusu olan, yıkıntılar içinde bir güzelliktir. Yıkım, enkaz fotoğrafları güzeldir. Gilles Peress, Susan Meiselas ve Joel Meyerowitz gibi mesleğinin usta fotoğrafçılarının çektikleri gerçekten güzel fotoğraflardır. (Sontag, 2004:76) 


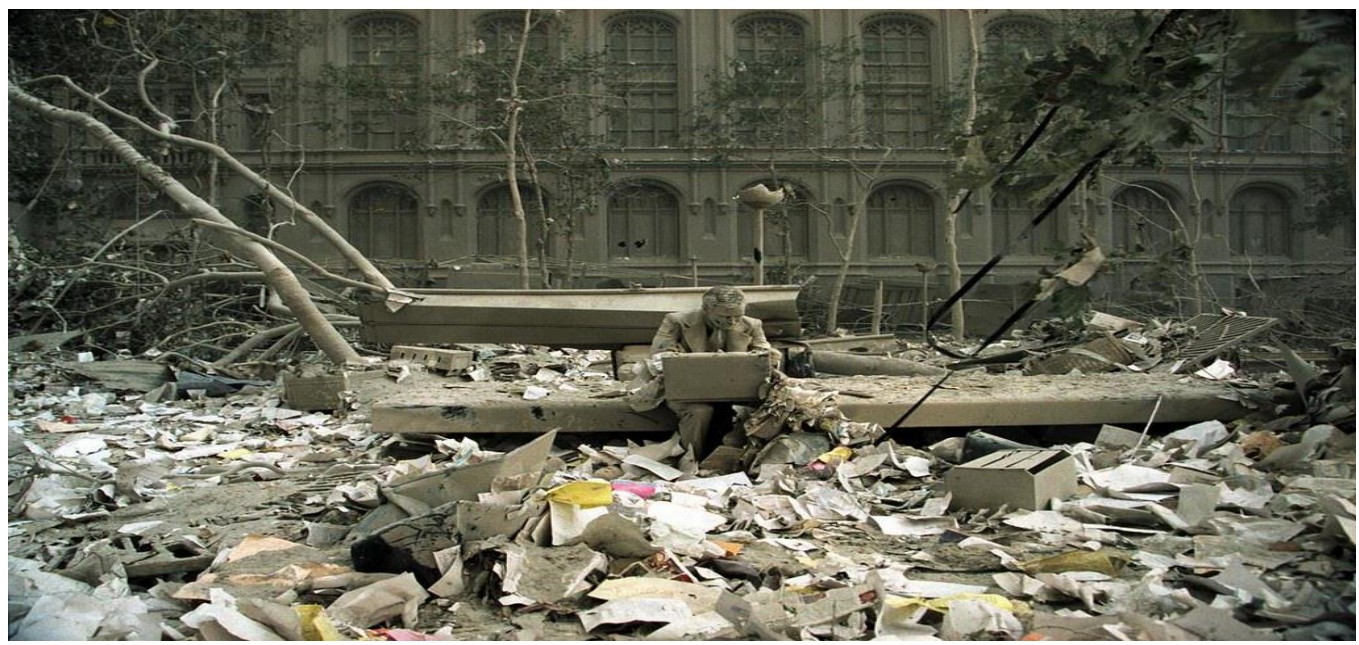

Görsel 16. Susan Meiselas (2001).

Time dergisine kapak olan 11 Eylül saldırı fotoğrafını çeken Kanadalı fotoğrafçı Lyle Owerko ise 11 Eylül'ü muhteşem bir tanıklık görüntüsü olarak değerlendirmektedir. Baudrillard'ın deyişiyle teröristlerin terör eylemleri gerçekleștirmelerinde insanı hem korkutan hem de büyüleyen bir şeyler vardır. Zira insanlar fiziksel bir yok oluş biçimine katlanabilirler ama bu yok oluş gösterisine tanık olamama gibi bir șeye katlanamazlar (Baudrillard, 2011a: 65-238).

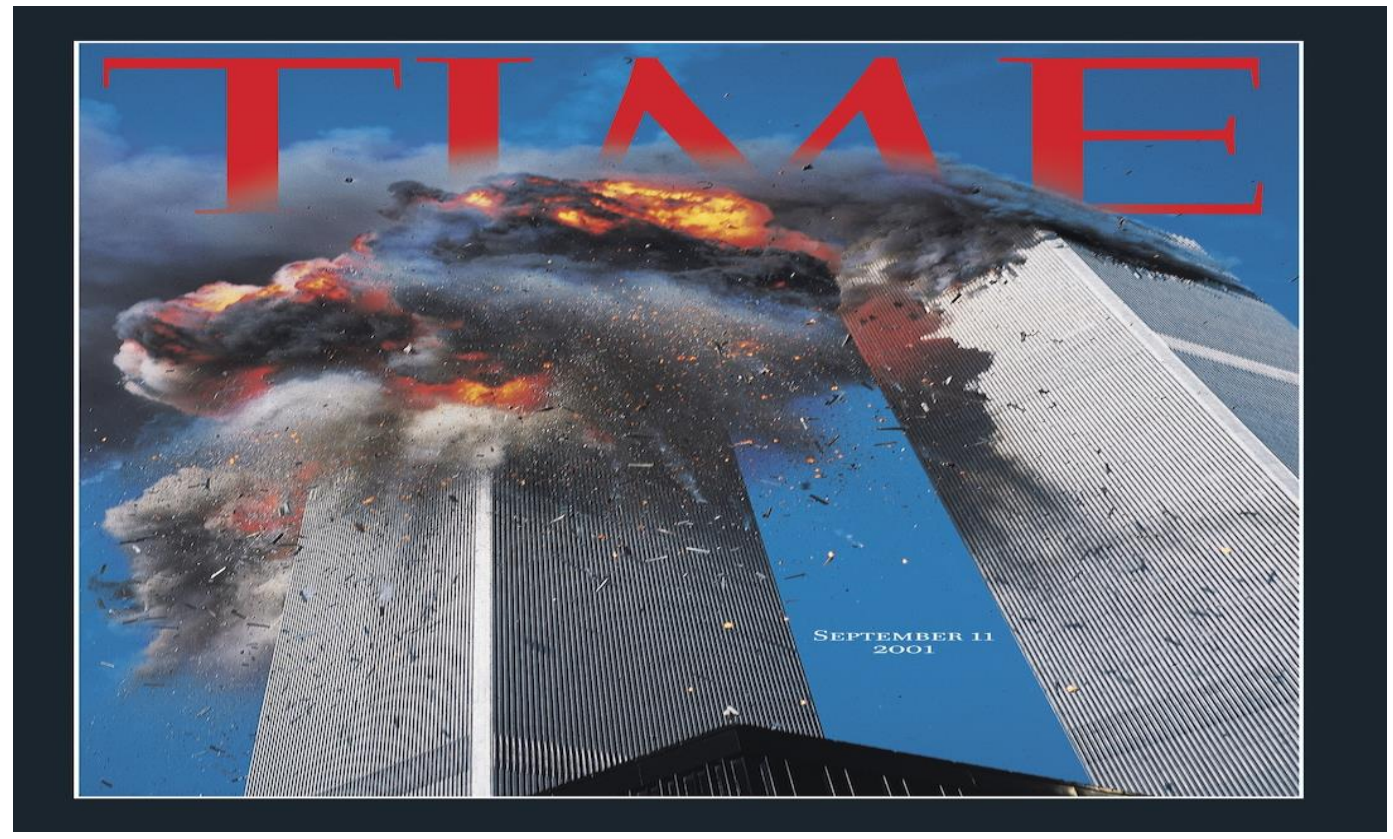

Görsel 17. Lyle Owerko (2001).

11 Eylül saldırısı ve fotoğrafları üzerine yapılan değerlendirmeler Potlacın yani armağan kültürünün ve zihniyetinin estetiğini yansıtmaktadır. El Kaide lideri Usame Bin Ladin'in verdiği potlaçta uçaklar armağan edilmiş, İkiz kuleler abartılı, aşırı, çarpıcı ve gösterişçi bir şekilde yıkıma uğratılmış, kitleler baştan çıkartılmış ve büyülenmişlerdir. Bu çerçevede Potlaç yıkıcı yüce olarak ta değerlendirilebilir.

11 Eylül saldırılarının ilkel toplumda, ortaçağda, erken modern dönemde ve 20 yüzyılın başında Çin'de gerçekleştirilen idam ritüellerinden, bedenlerin abartılı ve gösterişçi bir şekilde imhasından farkı bulunmamaktadır. Bu benzerlik armağan kültürünün ve zihniyetinin ilkelerinin ve estetik biçiminin 
varlığını sürdürdüğünün delili sayılabilir. George Bataille’nin 1961 yılında ölümüne kadar her gün bakmak için masasında bulundurduğu fotoğraf (Sontag, 2004: 98) adeta bunu kanıtlar gibidir.

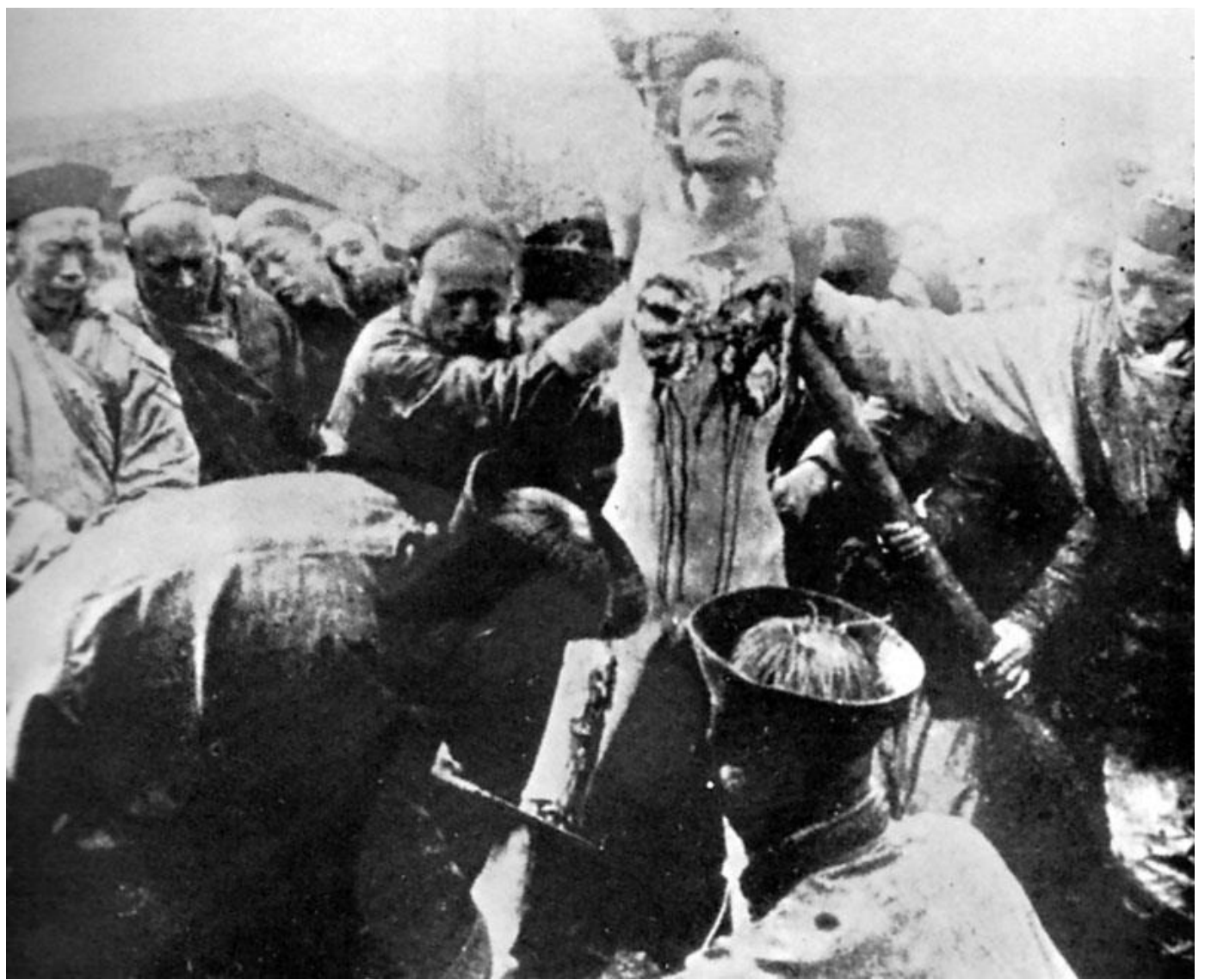

Görsel 18. Fransız asker tarafından çekilen fotoğraf, isimsiz, (Pekin, 1905).

İkiz kuleler yıkıma uğrayan, imha edilen bedenle eş tutulabilir. Bedene saplanan bıçak İkiz kulelere çarpan uçak gibidir. Bedenin kesilen, koparılan uzuvları ve akan kan ikiz kulelerden dökülen moloz yığınları ve toz bulutlarıdır.

\section{Sonuç}

Bu çalışmada Fotoğraf ve yıkım ilişkisinin özellikle savaş fotoğraflarında belirginleştiği gözlemlenmiştir. Savaş alanlarında yıkıma uğramış, imha edilmiş, parçalanmış bedenlerin, yapıların ve nesnelerin fotoğrafları kitlelerde büyük bir merak ve heyecan uyandırmıştır. Fotoğrafın keşfinden sonra yıkımın kuramsal çerçevede estetikleştirilmesi fütürizm ve faşizmin yıkımı ve imhayı içeren savaşı yüceltmeleri ile gündeme gelmiştir. Faşist estetik irdelendiğinde aşağılanma kaygısı, yüceltme, çelişki, abartma, çarpıtma, biçimini bozma, aşırılık, ölüm estetiği, büyüleme gibi kavramlar ön plana çıkmaktadır. Oysa antropolojik metinler incelendiğinde bu kavramların Faşizmden yüzyıllar önce de var olan armağan kültürü ve zihniyetinde olduğu görülmektedir. Yıkıma yönelik incelenen tarihsel metinler idam ritüelleri bağlamında ilkel toplum, ortaçağ, erken modern dönem ve 20. Yüzyıl başında Çin olmak üzere benzerlikler olduğunu göstermektedir. Bu dönemlerde yaşayan toplumların ortak özellikleri kapitalizm öncesi evrensel kültür olarak değerlendirilen armağan kültürü ve zihniyetinin egemen olduğu toplumlar olmasıdır. Bu nedenle yıkım estetiğinin kökenleri armağan kültürü ve zihniyeti çerçevesinde değerlendirilmiş ve bedenin ve mülklerin aşırı, abartılı, ve gösterişçi bir biçimde yıkıma uğratıldıkları ve imha edildikleri görülmüştür. Ayrıca bu kültür ve zihniyette hakaretlerin, mızrakların, yumrukların vb. armağan olarak kabul edildiği ve mutlaka karşılık verilmesi gerektiği saptanmıştır. En önemlisi armağan kültürü ve zihniyetinin ilkelerinin günümüzde varlığını devam ettirmesidir.

11 Eylül saldırısı değerlendirildiğinde de karşımıza rekabet, meydan okuma, prestij, onur, itibar, statü, aşağılanma vb. merkezli armağan kültürü ve zihniyeti çıkmıştır. Saldırıyı yapanlar altta kalmamak, onur, 
prestij, statü, itibar kazanmak ve en önemlisi atalar ve Allah adına bu eylemi gerçekleştirmişler, armağan kültürü ve zihniyeti gereği Amerika Birleşik Devletlerinin birinci körfez savaşında verdiği yıkımı çarpıcı bir biçimde, aşağılayarak yarattı̆̆ı etki itibarıyla fazlasıyla iade etmişlerdir.

Yıkım estetiği Sontag metinlerinden de anlaşılacağı gibi yıkım ve imha süreçlerinin güzellik üzerinden değerlendirilebileceğini iddia etmektedir. Estetiğin kapsamının genişletilmesi ve güzelliğin yanı sıra yüce, trajik, dramatik, çirkin değerinin de estetik kapsamına alınmasının yıkım estetiğinin daha iyi anlaşılabilmesine katkıda bulunmuştur. Böylelikle yıkım fotoğraflarını güzelliğin yanı sıra yüce, trajik, dramatik kavramaları üzerinden değerlendirmek mümkün olmuştur. Nitekim 11 Eylül saldırısı ve fotoğrafları Aristoteles'in katharsis kavramını ve Immanuel Kant ile Friedrich Schiller'in estetiğe dair yaklaşımlarını onaylar niteliktedir. Damien Hirst, Karlheinz Stockhausen, Richard Schechner, Miles Orvell, Baudrillard gibi sanatçılar ve düşünür akademisyenler 11 Eylül saldırılarının büyüleyici, hayranlık uyandıran, yüce, trajik, güzel, coşkulu, olağandışı, ürkünç, gerçekleştirilmesi imkansız bir sanat eseri olarak estetik bir haz verdiğini iddia etmişlerdir. Saldırıyı fotoğraflayan James Nachtwey, Joel Meyerowitz ve Lyle Owerko gibi fotoğrafçılarda 11 Eylül saldırısını güzel, korkunç güzellik ve muhteşem sözcükleriyle betimlemişlerdir.

Bu güzelliğin, dehșetin, yüceliğin, trajikliğin, büyüleyiciliğin, coşkunun, hayranlık uyandırmanın, korkunun ikiz kulelerin aşırı, abartılı ve gösterişçi yıkımından ve imhasından kaynaklanıyor olduğu göz önüne alındığında, bir sanat eseri olarak 11 Eylül saldırısının ve saldırı fotoğraflarının yıkım estetiği ile olan ilişkisinin köklerinin Armağan Kültürü ve zihniyetine kadar uzandığı açıkça görülmektedir.

\section{Kaynakça}

Adanır, O. (1994). Sinemada Anlam ve Anlatım. İzmir: Kitle Yayınları.

Adanır, O. (2000). Baudrillard'ın Simülasyon Kuramı Üzerine Notlar ve Söyleşiler. İzmir: Dokuz Eylül Yayınları.

Adanır, O. (2002). Eski Dünyaya Yeni Bir Bakıș. Kitap 3. İzmir: Dokuz Eylül Yayınları.

Adanır, O. (2015). Eski Dünyaya Yeni Bir Bakış. İzmir: Dokuz Eylül Yayınları.

Adanır, 0. (2003). Kültür ile Zihniyet. Doğu Batı Dergisi, 6(23).

Alamy.com, (...), Erişim Tarihi: 01.07.2021. https://www.alamy.com/stock-photo/lingchi.html

Alexander, J. C., Giesen, B., Jason, L. ve Mast, J. L. (Ed.). (2006). Social Performance: Symbolic Action, Cultural Pragmatics, and Ritual. Cambridge: Cambridge University Press.

Allen, V. L. ve Greenberger, D. B. (1978). An Aesthetic Theory of Vandalism. Crime \& Delinquency, 24(3), 309-321.

Aretoulakis, E. (2016). Forbidden Aesthetics, Ethical Justice, and Terror in Modern Western Culture. Maryland: Lexington Books.

Aristoteles (1987). Poetika. (Çev. İsmail Tunalı). İstanbul: Remzi Kitabevi.

Baker, G. (2005). Photography's Expanded Field. October, 114, 120-140.

Bataille, G. (1999). Lanetli Pay. (Çev. Mehmet Mukadder Yakupoğlu). Ankara: Mor Yayınları.

Bate, D. (2009). Photography: The Key Concepts. New York: Berg Publications.

Baudrillard, J. (2011a). Çaresiz Stratejiler. (Çev. Oğuz Adanır). İstanbul: Boğaziçi Üniversitesi Yayınevi.

Baudrillard, J. (2011b). Simülakrlar ve Simülasyon. (Çev. Oğuz Adanır). Ankara: Doğu Batı Yayınları.

Baudrillard, J. (2013). Faucault'yu Unutmak. (Çev. Oğuz Adanır). Ankara: Doğu Batı Yayınları.

Baudrillard, J. (2015). Şeytana Satılan Ruh ya da Kötülüğün Egemenliği. (Çev. Oğuz Adanır). Ankara: Doğu Batı Yayınları.

Baudrillard, J. (2016). Simgesel Değiş Tokuşv ve Ölüm. (Çev. Oğuz Adanır). İstanbul: Boğaziçi Üniversitesi Yayınları.

Benjamin, W. (2013). Fotoğrafın Kısa Tarihi. (Çev. Osman Akınhay). İstanbul: Agora Kitaplığı.

Bloch, M. (1983). Feodal Toplum. (Çev. Mehmet Ali Kılıçbay). Ankara: Savaş Yayınları.

Braun, E. (1996). Expressionism as Fascist Aesthetic. Journal of Contemporary History, 31(2), 273-292.

Bruni, L., ve Zamagni, S. (2013). Handbook on the Economics of Reciprocity and Social Enterprise. Cheltenham: Edward Elgar Publishing.

Burke, P. (2008). Kültür Tarihi. (Çev. Mete Tunçay). İstanbul: İstanbul Bilgi Üniversitesi Yayınları.

Canetti, E. (2006). Kitle ve Íktidar. (Çev. Gülşat Aygen). İstanbul: Ayrıntı Yayınları.

Chilvers, I. (Ed.). (1990). The Concise Oxford Dictionary of Art and Artists. Oxford: Oxford University Press.

Doğan, M. H. (1975). 100 Soruda Estetik. İstanbul: Gerçek Yayınevi.

Domus, (2006). Serhan Adanın Jean Baudrillard ile Söyleşisi. (Çev. Gül Keskin). Erişim Tarihi: 06.06.2021 https://v3.arkitera.com/h13491-serhan-adanin-jean-baudrillard-ile-soylesisi.html 
Elsaesser, T., Horwath, A., ve King, N. (2004). The Last Great American Picture Show: New Hollywood Cinema in the 1970s. Amsterdam: Amsterdam University Press.

Evers, K. (2013). Violent Modernists: The Aesthetics of Destruction in Twentieth-Century German Literature. Evanston: Northwestern University Press.

Feldgrauinfo, (2016). Erişim Tarihi: 10.06.2021 https://feldgrau.info/2010-09-02-14-48-28/15653podborka-foto-po-pmv-18

Harris, M. (1994). Yamyamlar ve Krallar. (Çev. M. Fatih Gümüş). Ankara: İmge Kitabevi Yayınları.

Harris, M. (1995). İnekler, Domuzlar, Savaşlar ve Cadılar. (Çev. M. Fatih Gümüş). Ankara: İmge Kitabevi Yayınları.

Huizinga, J. (2006). Homo Ludens: Oyunun Toplumsal İşlevi Üzerine Bir Deneme. (Çev. Mehmet Ali Kılıçbay). İstanbul: Ayrıntı Yayınları.

Huizinga, J. (1997). Ortaçağın Gün Batımı. (Çev. Mehmet Ali Kılıçbay). Ankara: İmge Kitabevi.

Kant, I. (2010). Güzellik ve Yücelik Üzerine Gözlemler. (Çev. Ahmet Fethi). İstanbul: Hil Yayınları.

Lacey, A. R. (1996). A Dictionary of Philosophy. New York: Routledge.

Lousa, T. (2016). Death Aesthetization in Contemporary Artistic Practices. Arte, Individuo y Sociedad, 28(2), 371-385.

Macneill, P. (2014). Ethics and the Arts. New York: Springer.

Matsumoto, D. ve Hwang, H. S. (2012). Culture and Emotion: The Integration of Biological and Cultural Contributions. Journal of Cross-Cultural Psychology, 43(1), 91-118.

Mauss, M. (2011). Sosyoloji ve Antropoloji. (Çev. Özcan Doğan). Ankara: Doğu Batı Yayınları.

Miller, W. I. (1996). Bloodtaking and Peacemaking. Chicago: The University of Chicago Press.

Mucchielli, A. (1991). Zihniyetler. (Çev. Ahmet Kotil). İstanbul: İletișim Yayınları.

Offer, A. (1997). Between the Gift and the Market: The Economy of Regard. Economic History Review, 50(3), $450-476$.

Orvell, M. (2006). After 9/11: Photography, The Destructive Sublime, and the Postmodern Archive. Michigan Quarterly Review, 45(2), 239-256.

Orvell, M. (2013). Photographing Disaster: Urban Ruins and the Destructive Sublime. Amerikastudien/American Studies, 58(4), 647-671.

Parlatır, İ., Gözaydın, N., ve Zülfikar, H. (1988). Türk Dil Kurumu Türkçe Sözlük. Ankara: Türk Tarih Kurumu Basım Evi.

Paxton, R. O. (2005). The Anatomy of Fascism. London: Vintage.

Prosser, J. (2017). Fotoğrafın Krizi: Vahşeti Fotoğraflamak. (Çev. Ayça Göçmen). İstanbul: Espas Yayınları.

Ruff, J. R. (2011). Erken Modern Avrupa'da Şiddet 1500-1800. (Çev. Didem Türkoğlu). İstanbul: Boğaziçi Üniversitesi Yayınevi.

Schaper, E. (2005). Beğeni, Yücelik ve Deha: Doğa ve Sanat Estetiği. Sonsuzluğun Sınırında: Immanuel Kant. Cogito, Sayı: 41-42 içinde, İstanbul: Yapı Kredi Yayınları.

Schechner, R. (2009). 9/11 as Avant-Garde Art?. PMLA, 124(5), 1820-1829.

Scott, George Ryley (2001). İşkencenin Tarihi. (Çev. Hamide Koyukan). Ankara: Dost Yayınları.

Simon, E. (2015). Çin Uygarlığı. (Çev. Oğuz Adanır). Ankara: Doğu Batı Yayınları.

Sontag, S. (2004). Başkalarının Acısına Bakmak. (Çev. Osman Akınhay). İstanbul: Agora Kitaplığı.

Sontag, S. (2008). Büyüleyen Fașizm. (Çev. Ertan Yılmaz). Sinema, İdeoloji, Politika; Sinemasal Yazılar 1: Büyüleyen Faşizm ve Diğer Yazılar içinde, Ankara: Nirengi Kitap.

Sontag, S. (2015). Yoruma Karşı. (Çev. Osman Akınhay). İstanbul: Agora Kitaplı̆̆ı.

Sweet, L. (1999). Soultsunami: Sink or Swim in New Millennium Culture. Michigan: Zondervan Publisher.

Tosun, A.F. (2017). 2000'li Yıllardan Günümüze Türk Sinemasında Şiddet İçerikli Korku Filmlerinin Zihinsel-Kültürel Arka Planı. Kesit Akademi Dergisi, Yıl 3, Sayı 9, 333-344.

Tunalı, İ. (1998). Estetik. İstanbul: Remzi Kitabevi.

Urbandictionary(2013),DestructionAesthetics,ErișimTarihi:01.06.2021,https://www.urbandictionary.com /define.php?term=Destruction\%20Aesthetics

Warren, L. (2006). Encyclopedia of Twentieth-Century Photography. New York: Routledge.

Ziss, A. (1984). Estetik. (Çev.Yakup Şahan). İstanbul: De Yayınevi. 


\section{Extended Abstract}

The word aesthetic, which the German philosopher Baumgarten used for the first time in his work called Aesthetica that was published in 1750, was discussed as a theory of free arts, the theory of inferior knowledge, thinking about beauty and an artistry science that is similar to mind. There is no consensus on the definition of aesthetics. However, with a general approach, the theoretical science of beauty in aesthetic art and life can be defined as the beautiful sense. In today's art world, the word aesthetic includes the concepts of tragic, supreme, dramatic and ugly as well as beauty. According to Kant, disaster can bring a joy that includes fear. Trepidation is supreme. If the supreme is beautiful in activating, it enthralls. There is not enough information about the definition of aesthetics of destruction in academic studies. The dictionary meaning of it is to find beauty and charm in the things that are broken, overthrown, destroyed, collapsed. Susan Sontag, whose texts are frequently used within the general framework of the study, defines the aesthetics of destruction as the beauties that are observed while buildings, cities, people, etc. causing related destruction and creating chaos. This descriptive approach brings to mind Immanuel Kant's thoughts on the feelings of beauty and supremacy in the context of aesthetics.

Attacks as of September 11 are examined in this study, it is important to expand the scope of aesthetics. Undoubtedly, these attacks are evaluated also through the concept of supreme, tragic and dramatic, along with the concept of beauty.

Destruction has been used frequently in painting, sculpture, etc. throughout the history of art as a theme. Therefore, artists dealing with the theme of destruction also aestheticized destruction. After the emergence of photography, Futurism and fascism are at the center of efforts to aestheticize destruction. In Marinetti's futurist manifesto, he glorified the destruction of cities, buildings and people by saying that war is beautiful, and positioned the destruction within the field of aesthetics. Similarly, fascism and fascist aesthetics also glorified war and brought people to a point where they can enjoy their own destruction.

Undoubtedly, the greatest destructions are experienced in wars. War photographs play an important role in aestheticizing destruction. War is a tragedy, a horror. Tragedy and horror create a sense of supremacy with Kantian thought. Photographs of the destruction of the World War I and II can be considered supreme in this frame.

Looking for the cultural and mental origin of the aesthetics of destruction in fascism may mislead us. The exaggeration and distortion, destruction and show-off approach of fascist aesthetics show themselves in the culture and mentality of potlatch, a universal culture before capitalism, and centuries before fascism. In this culture, insulting words, spears, fists, etc. are considered as a gift. There is an obligation to return exceedingly to the gifts given in the gift culture and mentality, which is a mutual obligation order. Reputation, prestige, honor, and respectability are vital. Every gift that cannot be reciprocated leads to the destruction of respectability, prestige and honor. In this culture and mentality, the theme of destruction and sacrifice comes to the forefront. Properties are fought. Excess, extravagant and ostentatious destruction of property and people in potlatch are sacrificial and execution rituals.

Photos of September 11 attack show exaggerated, ostentatious destruction-annihilation. This form of destruction leads us directly to Kant's and Schiller's concepts of beauty, supreme, tragedy, excess and fear. These features of the attack and its photographs have led various artists and academicians to claim that the attack is a work of art. The September 11 attack and the photographs that record this attack give aesthetic pleasure as a fascinating, awe-inspiring, supreme, tragic, beautiful, exuberant, extraordinary, terrifying, impossible work of art.

A similar approach is valid for the photographers who are viewing the attack. In particular, photographers such as James Nachtwey, Joel Meyerowitz and Lyle Owerko emphasized the beauty, the terrifying beauty and the magnificence of the attack. All this shows the reason why the September 11 attack and the photos of the attack are so admirable is the extremist, exaggerated and pretentious form of destruction of the gift culture and mentality. 